\title{
Battery sizing and rule-based operation of grid-connected photovoltaic-battery system: A case study in Sweden
}

Yang Zhang ${ }^{\mathrm{a}, \mathrm{b}^{*}}$, Anders Lundblad ${ }^{\mathrm{a}, \mathrm{c}}$, Pietro Elia Campana ${ }^{\mathrm{c}}$, Fabián Benavente Araoz ${ }^{\mathrm{a}}$, Jinyue

$$
\mathrm{Yan}^{\mathrm{a}, \mathrm{c}, *}
$$

${ }^{\text {a }}$ School of Chemical Science and Engineering, KTH Royal Institute of Technology, SE10044 Stockholm, Sweden

${ }^{\mathrm{b}}$ Ningbo RK Solar Tech. Ltd., 315200 Ningbo, China

${ }^{c}$ School of Business, Society \& Engineering, Mälardalen University, SE-72123 Västerås, Sweden

*Corresponding author: Yang Zhang \& Jinyue Yan

Mail address: Teknikringen 42, SE-11428 Stockholm, Sweden

Yang Zhang: yaz@kth.se

Anders Lundblad: 1undbla@,kth.se

Pietro Elia Campana: pietro.campana@mdh.se

Fabián Benavente Araoz: faba@kth.se

Jinyue Yan: jinyue@kth.se 
3 Abstract: The optimal components design for grid-connected photovoltaic-battery systems

\section{Battery sizing and rule-based operation of grid-connected}

\section{photovoltaic-battery system: A case study in Sweden} should be determined with consideration of system operation. This study proposes a method to simultaneously optimize the battery capacity and rule-based operation strategy. The investigated photovoltaic-battery system is modeled using single diode photovoltaic model and Improved Shepherd battery model. Three rule-based operation strategies - including the conventional operation strategy, the dynamic price load shifting strategy, and the hybrid operation strategy - are designed and evaluated. The rule-based operation strategies introduce different operation parameters to run the system operation. multi-objective Genetic Algorithm is employed to optimize the decisional variables, including battery capacity and operation parameters, towards maximizing the system's Self Sufficiency Ratio and Net Present Value. The results indicate that employing battery with the conventional operation strategy is not profitable, although it increases Self Sufficiency Ratio. The dynamic price load shifting strategy has similar performance with the conventional operation strategy because the electricity price variation is not large enough. The proposed hybrid operation strategy outperforms other investigated strategies. When the battery capacity is lower than $72 \mathrm{kWh}$, Self Sufficiency Ratio and Net Present Value increase simultaneously with the battery capacity.

Keywords: Photovoltaic; Battery; Operation Strategy; Optimization; Genetic Algorithm 


\begin{tabular}{|c|c|}
\hline Symbol & Description \\
\hline$C_{O \& M, y}$ & Operation and maintenance cost at year y \\
\hline$C_{R, y}$ & Replacement cost at year y \\
\hline$C A P_{i}$ & Capacity for component $i$ \\
\hline$d_{r}$ & Discount rate \\
\hline$E l_{r, t}$ & Retail electricity price at time $t$ \\
\hline$E l_{w, t}$ & Wholesale electricity price at time $t$ \\
\hline$E l_{r, H}$ & High retail electricity price \\
\hline$E l_{r, L}$ & Low retail electricity price \\
\hline $\operatorname{Inv}$ & Investment cost \\
\hline$P_{B, t}$ & Battery power at time $\mathrm{t}$ \\
\hline$P_{G, t}$ & Grid power at time $t$ \\
\hline$P_{G, p e a k}$ & Grid peak power \\
\hline$P_{\text {Gim }, t}$ & Imported grid power at time $\mathrm{t}$ \\
\hline$P_{G e x, t}$ & Exported grid power at time $\mathrm{t}$ \\
\hline$P_{L, t}$ & Load at time $\mathrm{t}$ \\
\hline$P_{M d i s c, t}$ & Maximal discharge power at time $t$ \\
\hline$P_{\text {Mchar }, t}$ & Maximal charge power at time $\mathrm{t}$ \\
\hline$P_{N e t, t}$ & Net power at time $t$ \\
\hline$P_{P V, t}$ & PV power production at time $t$ \\
\hline$P_{H}$ & High power limit \\
\hline$P_{L}$ & Low power limit \\
\hline$R_{y}$ & System revenue at year y \\
\hline$R_{E R, y}$ & Electricity reduction revenue at year y \\
\hline$R_{E X, y}$ & Export revenue at year y \\
\hline$R_{P S, y}$ & Peak shaving revenue at year $\mathrm{y}$ \\
\hline$r_{O \& M, i}$ & O\&M Ratio for component $i$ \\
\hline$S O C_{t}$ & State of Charge at time $t$ \\
\hline$t_{s}$ & Conventional operation start time \\
\hline$t_{e}$ & Conventional operation end time \\
\hline$t_{\text {peak }}$ & The appearance time of $P_{G, p e a k}$ \\
\hline$U I C_{i}$ & Unit Investment Cost for component $i$ \\
\hline$\eta_{\text {inv }}$ & Inverter efficiency \\
\hline
\end{tabular}

\section{Abbreviations}

\begin{tabular}{cl}
\hline Abbreviations & \multicolumn{1}{c}{ Description } \\
\hline DOD & Depth of Discharge \\
Elspot & Electricity Spot \\
EMS & Energy Management System \\
GA & Genetic Algorithm \\
LOC & Level of Confidence \\
NPV & Net Present Value \\
SOC & State of Charge \\
SSR & Self Sufficiency Ratio \\
TOU & Time-of-Use \\
\hline
\end{tabular}




\section{Introduction}

The installed Photovoltaic (PV) capacity has increased rapidly in recent years. The installed capacity has reached $177 \mathrm{GW}$ at the end of 2014 [1]. Supporting policies, including feed-intariff (Fit) and net-metering, are important incentives [2]. However, due to the intermittent nature of solar energy, the accumulated PV capacity in the grid brings in technical issues with power quality, frequency stability [3], and reliability. Batteries can not only smooth the PV output and alleviate the technical challenges [4], but also increase the economic benefits [5]. The interest in the grid-connected PV-battery system is increasing among researchers and owners [6].

Batteries can subject to different operation strategies and bring in different economic benefits. In the first place, batteries increase the self-consumed electricity through storing excess PV generation and discharging to supply consumption later [5]. The self-consumed electricity increases the economic benefits due to the higher economic value than exported electricity. A further battery management strategy is to charge it when the electricity price is low and discharge it during high price times (loading shifting) [7]. In this case, benefits can be achieved from the difference in electricity price. Furthermore, if the electricity user is partly charged based on the peak power, battery can be discharged during the peak demand (peak shaving) [8]. In this case, benefits are achieved through reducing the user's peak power.

During the planning stage of the grid-connected PV-battery system, PV and battery capacities need to be decided. Meanwhile, different operation strategies need to be taken into account to enhance the economic benefits. This is an optimization problem that simultaneously takes into account PV capacity, battery capacity, and operation strategy [9]. However, the literature survey indicates that component sizing and operation strategy are generally studied separately. There are many researches addressing the component sizing issue, especially for the off-grid systems. For example, Yang et al. used Genetic Algorithm and obtained the PV, wind turbine 
and battery capacity for a stand-alone system [10]. Paliwal et al. introduced particle swarm optimization method to determine the system configuration [11]. Xu et al. studied the possible combinations of various PV, wind turbine and battery capacities, and obtained the system design under either grid-connected or stand-alone condition [12]. Mulder et al. studied the relationship between battery capacity and exported electricity to the grid in a grid-connected PVbattery system. The relationship is further used to dimension the battery size [13]. Bortolini et al. carried out a techno-economic analysis and determined the PV and battery capacity to minimize the levelized cost of electricity in grid-connected PV-battery system [14]. Zhou et al. addressed the battery sizing issue with consideration of demand response under Time-of-Use (TOU) tariff [15]. Mokhtari et al. determined the component size through the optimization towards different objectives (i.e. maximizing power export) [16]. The above studies cover the component sizing issue. However, the issue of maximizing economic benefits with different operation strategies is not well addressed.

The optimal operation of a given system, which is achieved by Energy Management System (EMS), also attracts lots of research attention [17]. A short-term power scheduling model for a grid-connected PV-battery system was proposed by Lu et al. using a Lagrangian relaxationbased optimization algorithm [18]. Riffonneau et al. used dynamic programming and obtained the 24-hour ahead power scheduling based on the accurate prediction of weather and load [19]. Li et al. used dynamic programming to get predictive charge control strategies for different objectives (i.e. maximizing battery life, maximizing self-sufficiency) [20]. Marzband et al. proposed a power scheduling method based on mixed-integer nonlinear programming and verified it with test bench [21]. An EMS that was based on multi-layer ant colony optimization was reported to decrease the energy cost by $20 \%$ compared with the conventional EMS [22]. Gravitational Search Algorithm was demonstrated as an effective tool for peak consumption reduction and electricity generation cost minimization [23]. Imperialist competition algorithm was 
used in EMS to provide multiple optimum solutions [24]. When considering demand response of customers in the microgrid, further decrease of energy cost (30\%) was achieved [25]. The above studies obtained short-term power scheduling based on forecasted weather and load data. The optimal operation issue is well addressed. However, the components in the studied systems have pre-assumed and fixed sizes.

The literature survey indicates that studies on component sizing or optimal operation employ different approaches, which are differentiated by decisional variables (component sizes / power scheduling), input data (historical and representative data / forecasted data) and simulation time frame (year / day).

Studies that take into account both sizing and scheduling problems are generally scarce. $\mathrm{Ru}$ et al. determined the battery capacity in grid-connected PV-battery system with consideration of load shifting and peak shaving under TOU tariff [26]. However, the optimal battery capacity is determined based on the simulation of one typical day, indication that the seasonal variation of solar irradiation and load is not considered. Gitizadeh et al. [27] extended the research by $\mathrm{Ru}$ et al. Instead of one typical day, multiple typical operation scenarios, which are obtained from Fuzzy Clustering Method, are used in solving the optimization problem. Khalilpour and Vassallo proposed a decision support tool to decide system size concurrently with finding the optimal operation schedule [28]. The support tool offers users to choose among different PV and battery modules. The above studies merged component sizing and optimal scheduling. They carried out long period simulation (several days or one year) using the historical data as input, and determined the decisional variables including component sizes and power scheduling. However, because of the extremely large amount of decisional variables (i.e. 18, 659, 330 in Khalilpour and Vassallo [28]), the complex non-linear system was reduced to linear system to facilitate the problem solving. Moreover, the studies assumed that correct weather and load forecasting can be ensured during the real-time operation. 
In this study, a new approach of determining the battery capacity and operation strategy is proposed. Instead of determining the power scheduling, the new approach is based on rulebased operation strategy. The approach largely decreases the numbers of decisional variables and enables carrying out optimization with non-linear system. Specially, batteries are complex electrochemical devices. Their efficiency, power constraints and lifetime are all influenced by the operation condition. The approach enables to employ a more detailed model.

The main contributions of the paper are summarized below: 1) an approach that determines battery capacity with consideration of system operation is proposed. The approach differs with previous studies in using rule-based operation strategy and optimizing the operation parameters; 2) multi-objective optimization is carried out to analyze the feasibility of employing battery to improve PV system's performance in both the renewable energy penetration level and economic strategies; 4) the studied case locates in cold-climate area with serious seasonal mismatch between generation and consumption, and it belongs to a deregulated electricity market. Similar cases are rare in existing literature.

The article is organized as follows: Section 1 is introduction; Section 2 describes the methods; Section 3 presents results and carries out discussion; Section 4 summarizes the results and draws conclusion.

\section{Methods}

Sections 2.1-2.5 describe the grid-connected PV-battery system modeling. The major components as well as the employed mathematical models are described. Section 2.6 presents three operation strategies. Section 2.7 introduces the optimization objectives. Sections 2.8 describes the Genetic Algorithm.

\subsection{System Schematic Layout}


The system schematic layout is shown in Fig. 1. The system is grid-connected and consists of PV panels, battery packs, load of a typical residential building and grid. The PV panels and battery packs are respectively connected to the DC bus via MPPT (Maximal Power Point Tracking) converters and battery controllers. The load and grid are directly connected to the $230 \mathrm{~V}$ $\mathrm{AC}$ bus. The AC and DC buses are connected through bi-directional inverters. The inverter is assumed with fixed efficiency of $0.95\left(\eta_{\text {inv }}\right)$ [26]. The schematic layout in Fig. 1, as the simplified architecture of the actual system, is wildly used in studies on component sizing [12] and power scheduling [19]. The sign of power flows represents their direction. The arrows above each term indicate the directions of positive power flows. Negative values indicate that the power flows are in opposite directions. For example, positive and negative $P_{B, t}$ represent discharging and charging the battery, respectively. When $P_{G, t}$ is zero, the system works in islanded mode. The power flow equation and constraints, including power balance and physical constraints of system components, are detailed in Section 2.6.

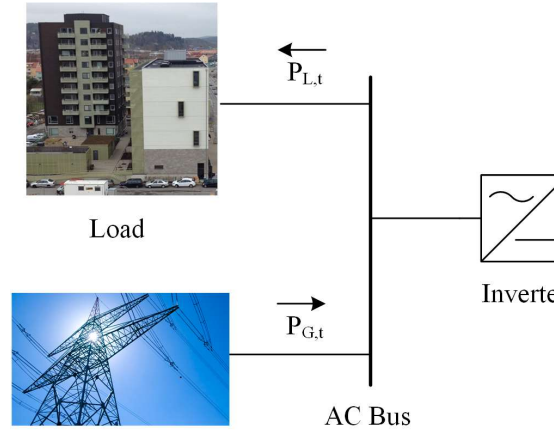

Grid

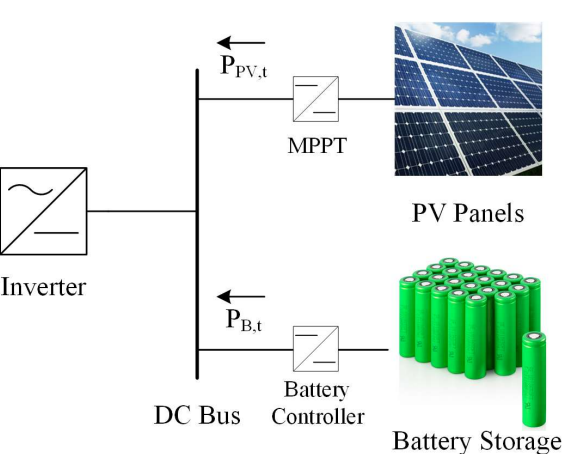

Battery Storage

Fig. 1. System schematic layout

The system simulation and optimization is carried out with MATLAB ${ }^{\circledR} 2015 \mathrm{~b}$ environment, and part of the code is based on open-source code, OptiCE [29].

\subsection{Single Diode Photovoltaic Model}

The single diode model [30] is represented by the electric circuit shown in Fig. 2. The nonlinear I-V curve of the PV module is obtained through Eq. (1): 


$$
I_{P V}=I_{P H}-I_{0}\left[\exp \left(\frac{V_{P V}+I_{P V} \cdot R_{S}}{a}\right)-1\right]-\frac{V_{P V}+I_{P V} \cdot R_{S}}{R_{S h}}
$$

where, $I_{P H}$ is the photocurrent (A); $I_{o}$ is the diode reverse saturation current (A); $a$ is the ideality factor $(\mathrm{V}) ; R_{S h}$ is the shunt resistance $(\Omega) ; R_{S}$ is the series resistance $(\Omega)$. They are calculated with the method in Duffie and Beckman [31] and De Soto et al.[30]. The cell temperature $T_{c}$ is approximated with method in Dolara et al. [32].

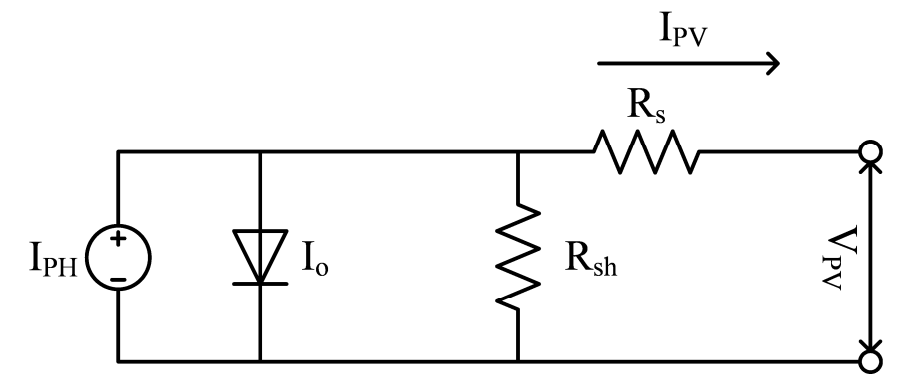

Fig. 2. Single Diode Model

\begin{abstract}
MPPT can ensure the maximal power output from PV. There are many studies about the
\end{abstract} MPPT topology design [33] and optimization [34]. In this study, MPPT controller is simulated with simplified approach described in Eq. (2) [35].

$$
P_{P V, m p p}=\max \left(I_{P V} \cdot V_{P V}\right)
$$

The PV module in this study comes from SUNTECH power and module No. is STP25520/Wd. This polycrystalline module has a maximal power output of $255 \mathrm{~W}$. The single diode model characterizing parameters are taken from the System Advisory Model [36]. The parameters are summarized in the Appendix (Table A1).

The azimuth angle and tilt angle of the PV are determined as $0^{\circ}$ and $36^{\circ}$, which maximize the total yearly electricity production. The hourly production profile from single PV module is shown in Fig. 3. 


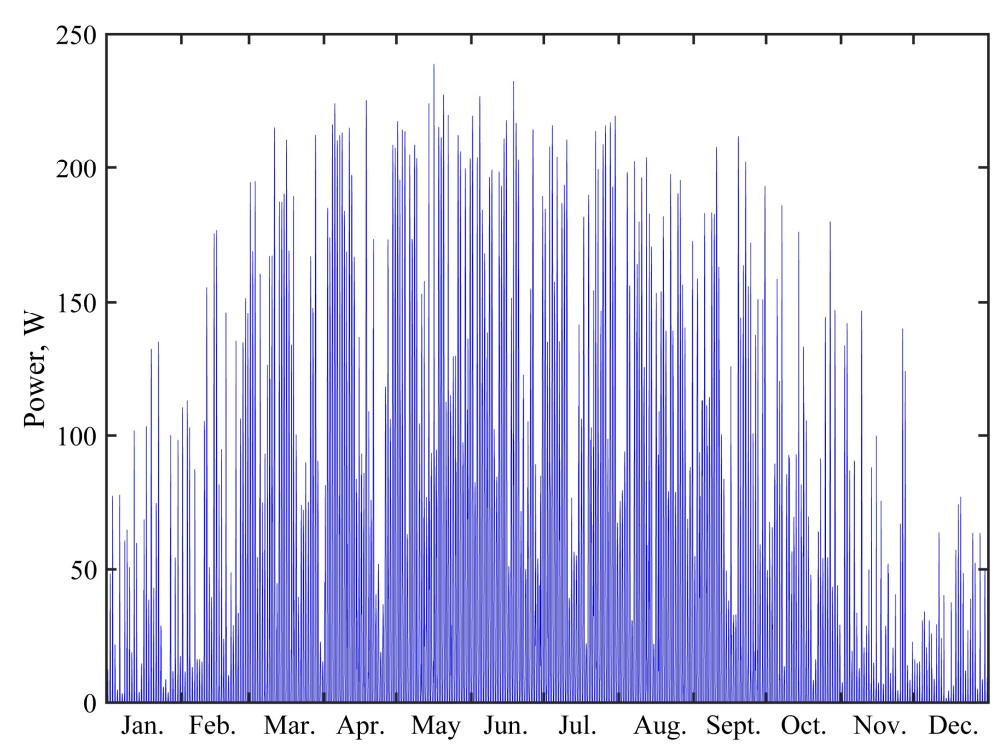

Fig. 3. Single module hourly power production with azimuth angle of $0^{\circ}$ and tilt angle of $36^{\circ}$

\subsection{Battery Model}

There are several types of battery suitable for energy storage. Lithium ion battery outperforms other types in energy density, power density and round trip efficiency. It also has long cycle life, which means less replacement times and cost [37]. In recent years, with the strong boost from electrical vehicle industry, the lithium ion battery cost has dropped substantially and is expected to drop continuously [38]. In this study, lithium ion battery is used for energy storage.

\subsubsection{Battery Voltage Current Model}

Improved Shepherd model, developed by Tremblay et al. [39], is employed in this study. The model describes the voltage-current relationship with consideration of SOC. The battery equivalent circuit is shown in Fig. 4. The charge and discharge characteristics are represented by Eqs. (3) and (4), respectively: 
where, $V$ is the battery voltage $(\mathrm{V}) ; E_{0}$ is the battery open circuit voltage (V); $K$ stands for the polarization constant $(\mathrm{V} /(\mathrm{Ah}))$ and polarization resistance $(\Omega)$; $\mathrm{Q}$ is the battery capacity; $\int$ it is the accumulated battery charge; $A$ is the exponential zone amplitude (V); $i$ is the battery current; $i^{*}$ is the filtered current; $R$ is the internal resistance $(\Omega) ; B$ is the exponential zone time constant inverse $(\mathrm{Ah})^{-1}$.

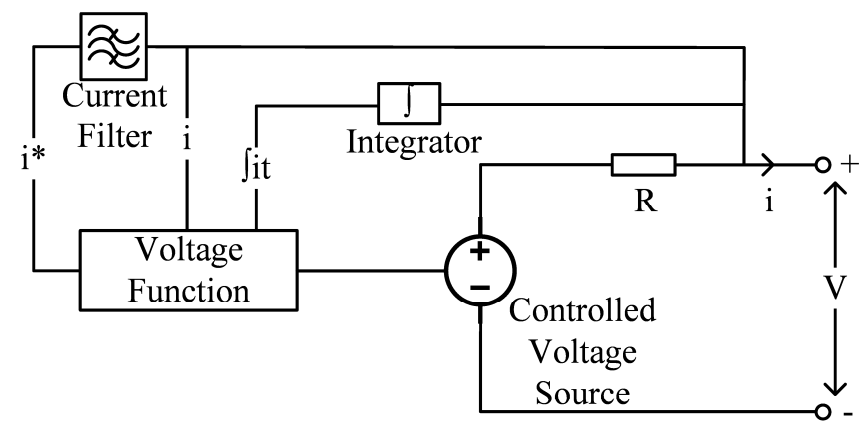

Fig. 4. Battery equivalent circuit

The battery parameters are taken from Tremblay et al. [39] and summarized in the Appendix (Table A2).

\subsubsection{Battery Life Time Model}

The battery lifetime is usually tested with standard charging and discharging cycles. As shown in Fig. 5, the number of life cycles decreases with the Depth of Discharge (DOD). The data from Wang et al. [40] is fitted with the three-parameter equation Eq. (5) [41].

$$
N=\frac{C}{(D O D-d)^{m}}
$$

$\mathrm{N}$ is the number of cycles before the end of life (i.e. $80 \%$ remaining capacity), DOD is the depth of discharge, $C, d$ and $m$ are parameters to be decided through fitting. 


$$
L=\min \left(L_{\text {cycle }}, L_{\text {calendar }}\right)
$$

$$
L_{\text {cycle }}=\frac{N_{s t}}{N_{\text {red }}}=\frac{N_{s t}}{\sum\left(\frac{D O D_{i}-d}{D O D_{S T}-d}\right)^{m} \times R_{i}}
$$

where, subscript $i$ indicates for $i^{\text {th }}$ microcycle; $N_{\text {st }}$ is the cycle numbers at standard test condition; $D O D_{S T}$ is the DOD under standard test condition ( $80 \%$ ); $R_{i}$ is 0.5 (Half Cycle) or 1 (Full cycle).

Fig. 5. Number of cycles vs. battery DOD, data from Wang et al. [40] and fitting result

The battery charge and discharge cycles under working conditions are composed of several micro cycles with different DOD. The Rainflow counting method is employed to decompose the complex cycles to micro cycles of different DOD. The method is firstly reported by Downing et al.[42] and has been employed in renewable energy system study [43]. The decomposed micro cycles with different DOD are further converted to standard cycles at $80 \%$ DOD $\left(N_{\text {red }}\right)$, and the cycle lifetime $\left(L_{c y c l e}\right)$ is calculated with Eq. (6):

$$
\text { Battery lifetime is further evaluated with consideration of the calendar life, which is } 15 \text { years }
$$
in this study [44].

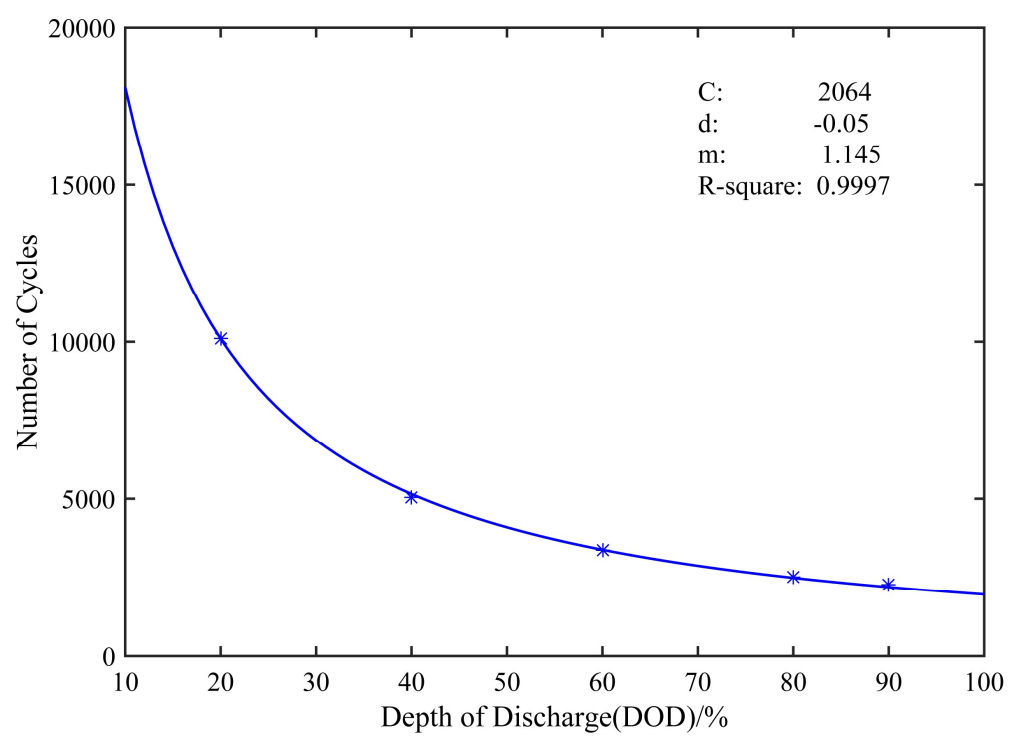




\subsection{Load and Weather Profiles}

The hourly electricity consumption (Fig. 6) of a rental multi-apartment building (Fig. 7) in

218 Gothenburg $\left(\mathrm{N} 57.70^{\circ}, \mathrm{W} 11.98^{\circ}\right)$ is recorded from the building owner, Wallenstam AB.

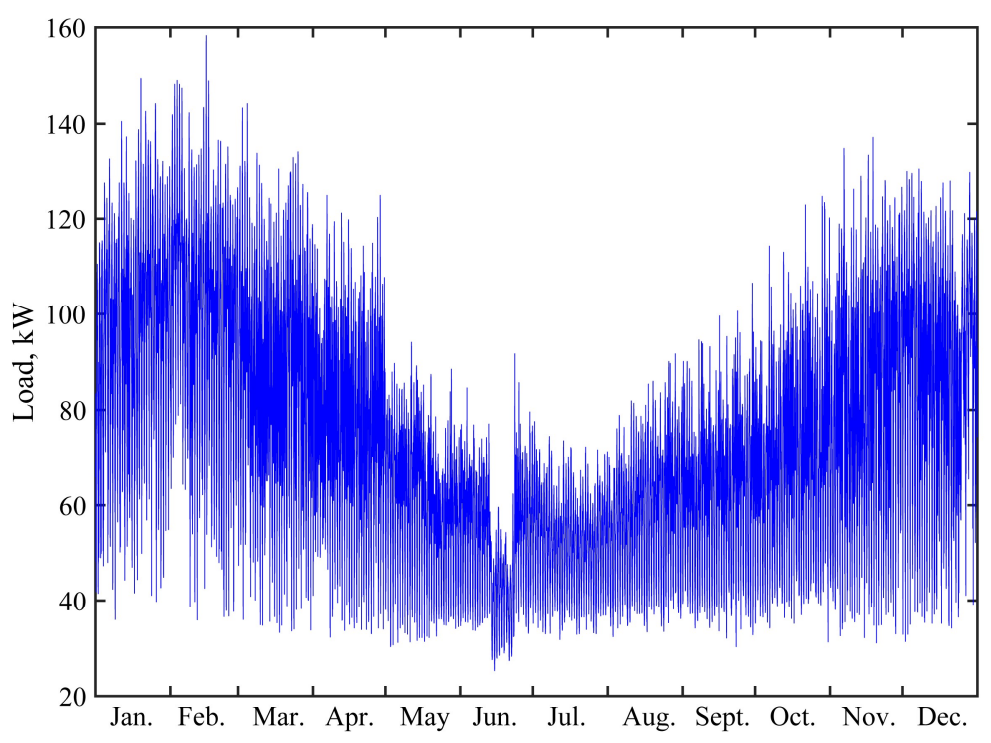

Fig. 6 Hourly electricity consumption of the studied case

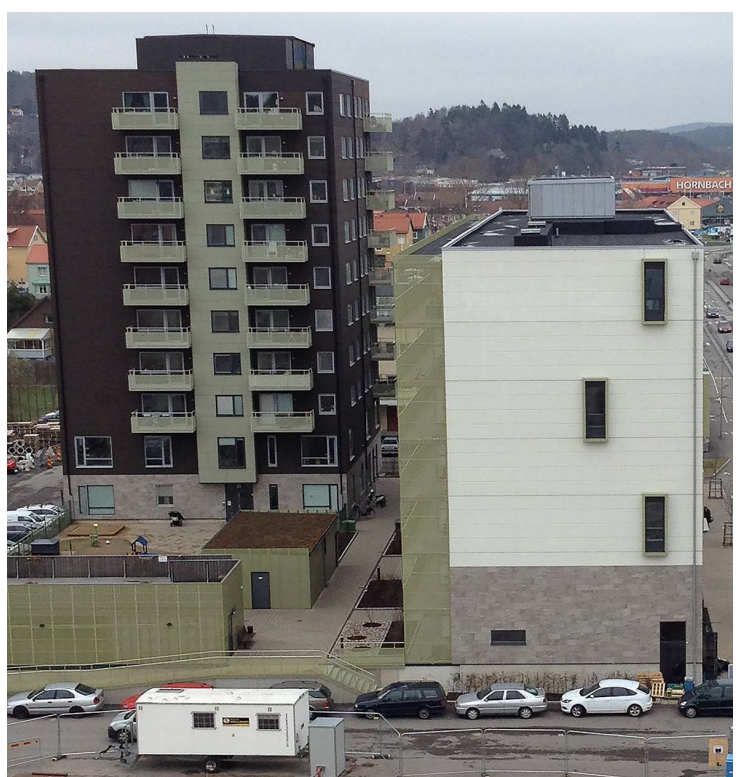

Fig. 7. The studied case: a rental multi-apartment building in Gothenburg

The weather data in Gothenburg — including global horizontal radiation $\left(\mathrm{W} / \mathrm{m}^{2}\right)$, diffuse a global climatic database, Meteonorm [45]. 
Seasonal mismatch can be found between PV production profile (Fig. 3) and load profile

228

229

230

(Fig. 6). During cold months, the PV production is low, while the consumption is high. Vice versa during warm months. More detailed analysis about the mismatch, including average daily profile in typical months, can be found in our previous study [46].

\subsection{Local Electricity Market and System Revenue}

The retail electricity price in Sweden depends on factors including client types, areas, local electricity market, taxes, etc. [47]. For the studied building, the retail electricity price can be decomposed into two variable components (Electricity Spot Price and Grid Fee) and one fixed component (Fixed Fee), as shown in Fig. 8. The Electricity Spot Price (Elspot price) is the day ahead hourly price from the bidding electricity market Nord Pool [48]. The fixed fee includes energy tax, green electricity certificate, fixed grid charge, VAT, etc. The grid fee depends on the maximal hourly power within the calendar year.

The hourly Elspot price in 2014 and its histogram are shown in Fig. 9. Throughout the whole year, the Elspot price varies between 0-0.95 SEK/ $/ \mathrm{Wh}$, while it mainly remains between 0.2 and $0.4 \mathrm{SEK} / \mathrm{kWh}$ (8046 hours of 8760 hours).

Under the local electricity market policy, the economic benefits from the PV-battery system can be categorized into three parts. The first part is the electricity reduction revenue $\left(R_{E R, y}\right)$, which comes from the load met by the PV-battery system. The self-consumed electricity price is the retail price $\left(E l_{r, t}\right)$, which is assumed to be the Elspot price plus $0.83 \mathrm{SEK} / \mathrm{kWh}$ (including grid fee and fixed fee). This is based on the current contract between the building owner and distribution system operator. This is consistent with the study by Sommerfeldt et al. [5]. 


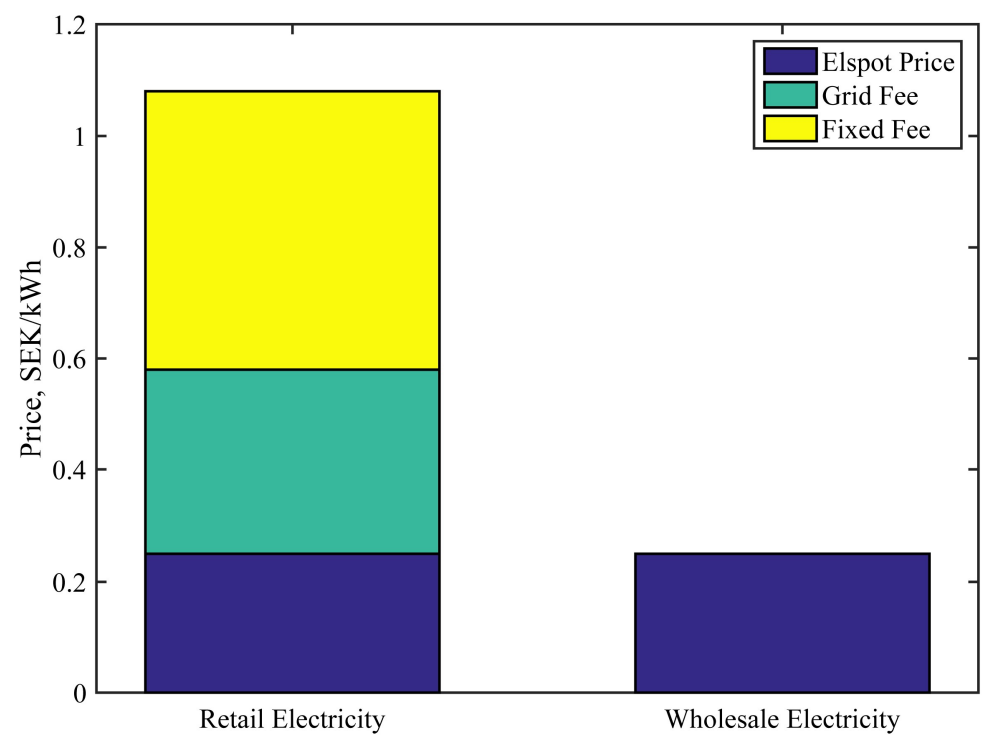

Fig. 8. Retail and wholesale electricity price
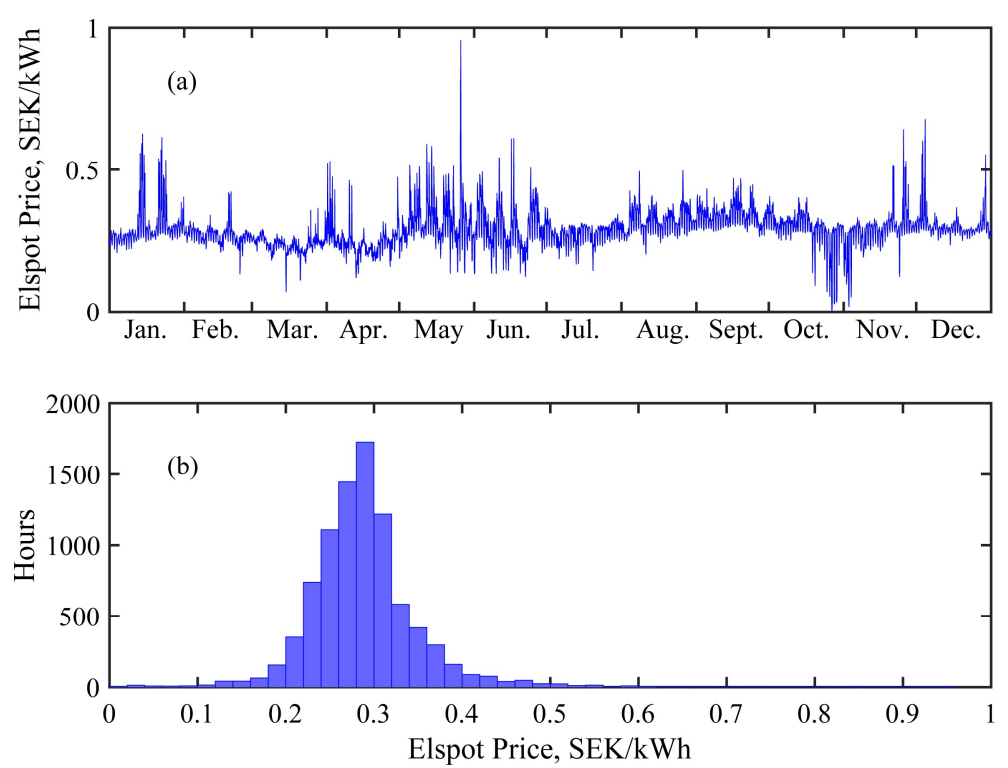

Fig. 9. (a) Hourly profile and (b) histogram of the Elspot price.

254 The second part is the electricity export revenue $\left(R_{E X, y}\right)$, which means that the surplus elec255 tricity generated by the system will be exported to the grid. The exported electricity is sold at 256 the wholesale price $\left(E l_{w, t}\right)$, namely the Elspot price [5]. Although there are some subsidies for 257 the exported electricity, like grid benefit compensation and green electricity certificate [47], 258 they are not taken into account due to uncertainties of these subsidies in the future [6]. 
The third part originates from carrying out peak shaving, thereby decreasing the grid fee (peak shaving revenue, $R_{P S, y}$ ). Detailed description of the peak shaving strategy is discussed in section 2.6. The reduced grid fee is assumed to be $1500 \mathrm{SEK} / \mathrm{kW} \cdot$ Year, which is obtained from the building owner according to the current contract.

The system revenue is summarized in Eq. (8):

$$
R_{y}=R_{E R, y}+R_{E X, y}+R_{P S, y}
$$

where, $R_{E R, y}$ is calculated with Eq. (9), $R_{E X, y}$ is calculated with Eq. (10), and $R_{P S, y}$ is calculated with Eq. (11).

\subsection{Operation Strategies}

Three rule-based operation strategies are described in this section. Within each operation strategy, there are different operation conditions that are determined by the operation parameters. Each operation condition is represented by a linear programming problem. At time $t$, load $\left(P_{L, t}\right)$ and PV production $\left(P_{P V, t}\right)$ are known values. Battery power $\left(P_{B, t}\right)$ and grid power $\left(P_{G, t}\right)$ are determined through solving the linear programming problem.

\subsubsection{Conventional Operation Strategy}

The commonly employed operation strategy [14] ("Conventional Operation Strategy”) for

$P_{L, t}$ is the load at time $\mathrm{t} ; P_{\text {Gim }, t}$ and $P_{G e x, t}$ are imported and exported grid power at time $\mathrm{t}$. 
282 is charged; surplus power after charging the battery is exported to the grid; when the PV pro-

283 duction cannot meet the load $\left(P_{P V, t}-\frac{P_{L, t}}{\eta_{i n v}}<0\right)$, the battery is discharged; if energy gap still

284 exists, the grid power is used. Batteries in the conventional operation strategy act as buffers

285 between generation and consumption. They increase the self-consumed electricity and system

286 revenue.

287 The operation strategy has one operation condition as depicted in Fig. 10. The objective

288 (C.Objective) is to minimize the absolute value of grid power $P_{G, t}$. Constraint $\left(P_{P V, t}+\right.$

$\left.289 P_{B a t t, t}\right) \eta_{i n v}=P_{L, t}-P_{G, t}$ is the power flow equation, which has to be satisfied at time $t$ to en-

290 sure the system reliability. Constraint $\left(P_{P V, t}-\frac{P_{L, t}}{\eta_{i n v}}\right) \cdot P_{G, t} \leq 0$ indicates that $P_{G, t}$ and $\left(P_{P V, t}-\right.$

$\left.291 \frac{P_{L, t}}{\eta_{i n v}}\right)$ have opposite signs. Constraint $P_{P V, t}+P_{B, t} \geq 0$ indicates that the DC side always exports

292 electricity to the AC side and that battery is not charged from AC side power. $P_{M d i s c, t}$ and

$293 P_{\text {Mchar }, t}$ are the maximal discharge and charge power (discharge power has positive sign). They

294 are determined by constraints including voltage, current and SOC, which are built inside the

295 battery model.

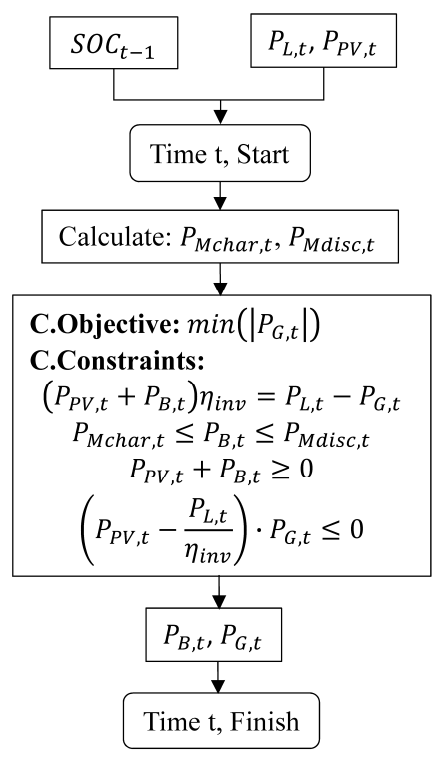




\subsubsection{Dynamic Price Load Shifting Strategy}

300

301

302

303

304

305

306

307

The PV-battery system can get extra benefits from the dynamic electricity price. The battery stores electricity at low price and provides electricity at high price. To realize this ("Dynamic Price Load Shifting Strategy" in the study), two operation parameters (high retail electricity price $E l_{r, H}$ and low retail electricity price $E l_{r, L}$, are introduced with referring to Dusonchet et al. [7]. The 24-hour ahead price information is fed to the controller to determine the system operation condition at time $t$. The flowchart of the operation strategy, which has three operation conditions, is depicted in Fig. 11.

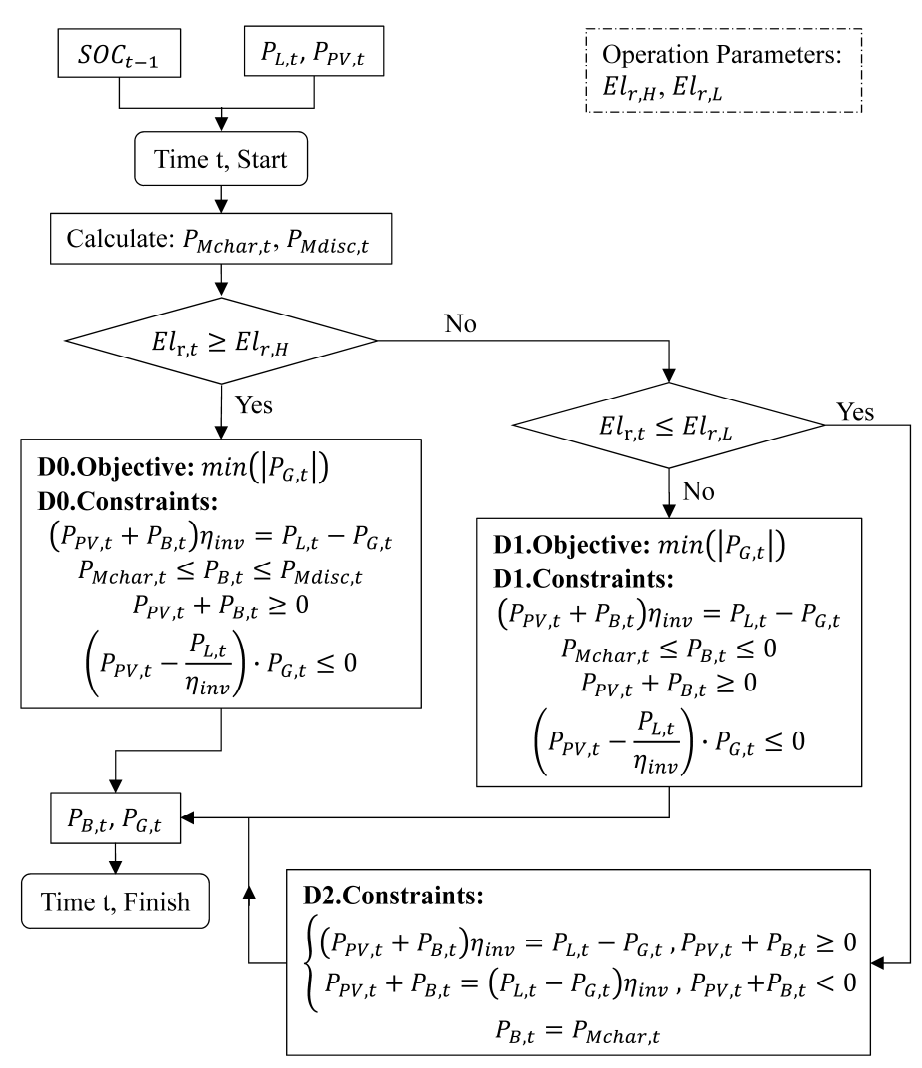

Fig. 11. Flowchart of the dynamic price load shifting strategy

If $E l_{r, t}$ is higher than $E l_{r, H}$, the system follows the operation condition D0 (same as the operation condition C). If $E l_{r, t}$ is lower than $E l_{r, L}$ (operation condition D2), battery is charged at $P_{\text {Mchar, } t}$. The system power balance is represented by two equations considering the power flow direction through the inverter. When $E l_{r, t}$ is between $E l_{r, L}$ and $E l_{r, H}$ (operation condition D1), 
314 the battery is not allowed to be discharged (constraint $P_{M c h, t} \leq P_{B, t} \leq 0$ ), but can be charged

315 if there is excess PV production.

316 When employing this operation strategy, three decisional variables, including battery capac-

317 ity $C A P_{b a t t}$ and two operation parameters $\left(E l_{r, H}\right.$ and $\left.E l_{r, L}\right)$, should be optimized.

\subsubsection{Hybrid Operation Strategy}

Rule-based peak shaving is achieved through maintaining high battery SOC [19]. While with the conventional operation strategy, battery SOC is more flexible that it changes with the load and production. There is conflict between the two operation strategies.

As previously analyzed in section 2.4 , PV production and load show significant seasonal variation. This suggests that single operation strategy (either conventional operation or peak shaving strategy) may not be appropriate all the year around. During cold and dark months, when PV production is low, the battery contributes little to improving the system performance with the conventional operation strategy. However, electricity demand is high at this time, thus the battery can be effectively used to decrease the peak power. While during warm months, the peak shaving strategy is no longer advantageous, since it prevents the battery from storing excess electricity and increasing the revenue.

Based on the discussion above, an overall approach ("Hybrid Operation Strategy" in this study), which includes both conventional operation and peak shaving, is proposed. The operation strategy includes four operation conditions, which are summarized in Fig. 12.

Four operation parameters $\left(P_{H}, P_{L}, t_{s}\right.$ and $\left.t_{e}\right)$ are introduced to realize the hybrid operation strategy. When time $t$ is between the conventional operation start time $t_{s}$ and end time $t_{e}$, the system follows the operation condition $\mathrm{H} 0$ (same as the operation condition C in Fig. 10). When time $t$ locates outside, the system carries out peak shaving, which is achieved through three operation conditions. At each time $t$, the net power $P_{N e t, t}\left(P_{N e t, t}=\left(P_{L, t}-P_{P V, t} \cdot \eta_{\text {inv }}\right)\right)$ is 
compared with high power limit $P_{H}$ and low power limit $P_{L}$. When $P_{N e t, t}$ is higher than $P_{H}$ (operation condition $\mathrm{H1}$ ), the battery is discharged. The discharge process maintains the grid power,

340 if possible, to be $P_{H}$ (objective: $\min \left(P_{G, t}\right)$ and constraint: $P_{G, t} \geq P_{H}$ ). The battery is not dis-

341 charged at the highest available power. Therefore, it reserves stored electricity and prepares for

342 the possible future peak. When $P_{N e t, t}$ is lower than $P_{L}$ (operation condition H3), the battery is

343 charged. The charge process is different from that in the dynamic price load shifting strategy

344 because grid power is limited below $P_{H}$. When $P_{N e t, t}$ is between $P_{H}$ and $P_{L}$, the battery is nei-

345 ther charged nor discharged. A Figure that presents $P_{N e t, t}, t_{s}, t_{e}, P_{H}$ and $P_{L}$ is shown in Fig. 13.

346 When PV capacity is fixed, there are five decisional variables $\left(C A P_{b a t t}, P_{H}, P_{L}, t_{s}\right.$ and $\left.t_{e}\right)$.

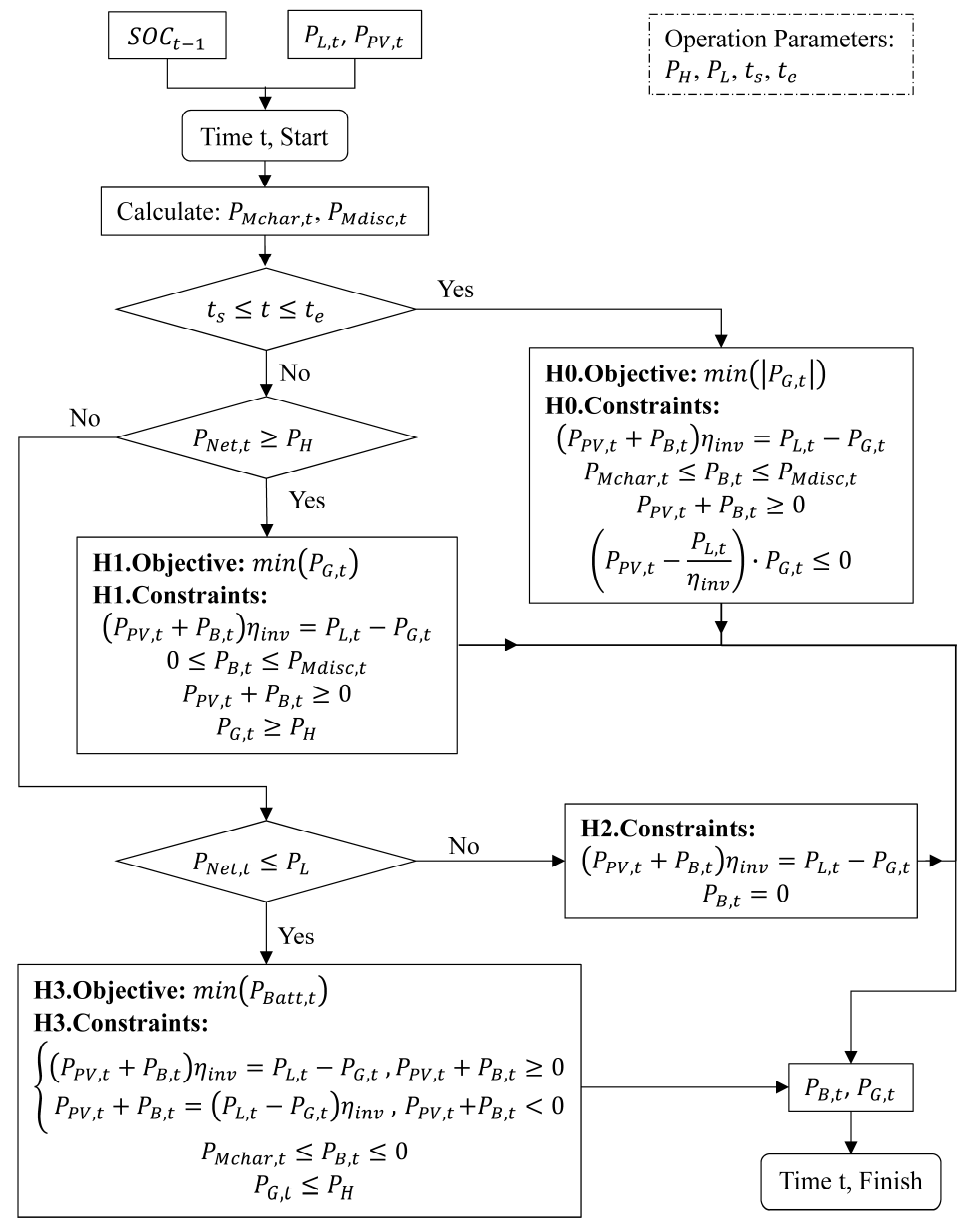

Fig. 12. Flowchart of the hybrid operation strategy 


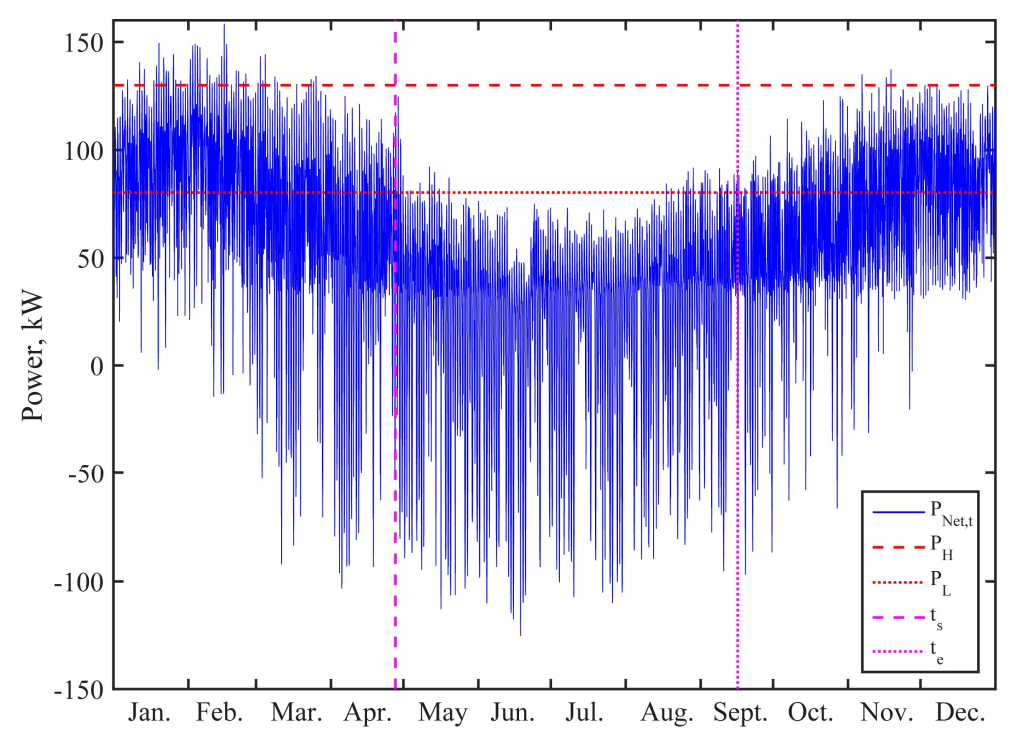

Fig. 13. Net power and the hybrid operation strategy parameters

\subsection{Objectives}

In renewable energy systems, there is usually trade-off between the economic and environmental goals. Two objectives, which are maximizing Net Present Value (NPV) and maximizing Self Sufficiency Ratio (SSR), are used to represent the economic goal and environmental goal, respectively.

NPV represents the economic benefits of the system. NPV (Eq. (14)) takes into account the system investment cost (Inv), Operation and Maintenance cost $\left(C_{O \& M, y}\right)$, replacement $\operatorname{cost}\left(C_{R, y}\right)$ and system revenues $\left(R_{y}\right)$ within the system life time (25 years). The discount rate $\left(d_{r}\right)$ is chosen as $2 \%$, considering current loan rate [49] and interest deduction for PV-related systems in Sweden [47].

$$
N P V=\sum_{y=1}^{25} \frac{\left(R_{y}-C_{O \& M, y}-C_{R, y}\right)}{\left(1+d_{r}\right)^{y-1}}-\operatorname{Inv}
$$

The cost information for battery system and PV system is listed in Table 1. Battery system price is taken from Tesla Powerwall [50], which includes battery pack and charge controller. PV system price is obtained from the Swedish PV market report of 2014 [47]. The price is turnkey cost, including inverter, installing and balance-of-plant cost. Because all components 
in the PV-battery system has been included in either battery system or PV system, it is assumed that the PV-battery system cost equals the PV system cost and the battery system cost, as represented in Eq. (15).

$$
I n v=U I C_{\text {batt }} \cdot C A P_{\text {batt }}+U I C_{P V} \cdot C A P_{P V}
$$

Table 1. Unit investment cost, lifetime and O\&M ratio of different components.

\begin{tabular}{cccc}
\hline Module & Unit Investment Cost $(U I C)$ & Life Time & O\&M Ratio $\left(r_{O \& M}\right)$ \\
\hline Lithium ion Battery System & $3966 \mathrm{SEK} / \mathrm{kWh}$ & Life time model & $0.5 \% /$ Year \\
PV system & $12900 \mathrm{SEK} / \mathrm{kW}$ & 25 Years & $1 \% /$ Year \\
\hline
\end{tabular}

$C_{R, y}$ is assumed same as the investment cost. The battery replacement time is determined by the lifetime model. $C_{O \& M, y}$ is assumed same in each year. It is calculated as:

$$
C_{O \& M, y}=U I C_{b a t t} \cdot C A P_{b a t t} \cdot r_{O \& M, b a t t}+U I C_{P V} \cdot C A P_{P V} \cdot r_{O \& M, P V}
$$

SSR is another objective. SSR is defined with Eq. (17) [6]. It represents the renewable energy penetration level of the system. The higher the SSR, the "greener" the system is.

$$
S S R=\left(1-\frac{\sum_{1}^{8760} P_{G i m, t}}{\sum_{1}^{8760} P_{L, t}}\right) \cdot 100 \%
$$

\subsection{Genetic Algorithm}

During the system planning stage of grid-connected PV-battery system, the decisional variables include component sizes and operation parameters (Section 2.6). The objectives include NPV and SSR. The attempt to go through all the combinations of decisional variables is unsuitable because of the extremely large amount of possible combinations and high computational time (Appendix, Table A3). Moreover, due to the complexity of the system (non-linear, nondifferentiable), traditional iterative methods cannot be applied either. To solve this multi-objective optimization problem, Genetic Algorithm (GA) is employed. As a population-based approach, GA is one of the most popular heuristic approach to multi-objective optimization problems [51]. Its advantages mainly include supporting black-box simulation models, being suitable for both continuous and discreet problem, etc. Moreover, it is inherently parallel, which makes it quite advantageous to carry out distributed computation. It has been extensively used 
and tested in the studies of renewable energy systems. Examples are summarized in a review paper of Chauhan and Saini [52].

The overall flowchart of the optimization process is shown in Fig. 14. The employed GA comes from the global optimization toolbox of MATLAB ${ }^{\circledR}$ and the configuration parameters (Table 2) are following MATLAB ${ }^{\circledR}$ suggestion. This study employs the adaptive stop criterion. If the weighted average relative change in the spread of the Pareto solutions over 100 (Stall Generations) generations is less than 0.0001 (Function Tolerance), the optimization algorithm stops. To avoid endless iterations when the optimization fails to converge, additional stop criterion with maximal generations of 300 , is added. In this study, all the performed optimizations are terminated by the adaptive stop criterion.

Table 2. GA configuration parameters

\begin{tabular}{cc}
\hline GA Configuration Parameter & Description \\
\hline Population size & $50 * / 200$ \\
Algorithm & Variant of NSGA II [53] \\
Elite fraction & 0.05 \\
Distance crowding & Phenotype (function space) \\
Pareto fraction & $0.6^{*} / 0.35$ \\
Selection & Tournament \\
Tournament size & 4 \\
Crossover function & Heuristic \\
Crossover ratio & 1.2 \\
Mutation function & Adaptive Feasible \\
Maximal generations & 300 \\
Stall generations & 100 \\
Function tolerance & 0.0001 \\
\hline For GA with the dynamic price load shifting strategy (Section 3.2)
\end{tabular}

Ideally, GA helps to solve the optimization problem and provide the relationship between SSR and NPV in the form of Pareto front. However, as GA is a heuristic tool, it cannot guarantee to reach the globally optimal solution. The near-optimal Pareto front is thus obtained. It should be noted that GA employs unguided mutation, which could lead to convergence at local 
410 parameters. Other heuristic tools, including Ant Colony Optimization and Particle Swarm Op-

411 timization, are used in the study of renewable systems and might also be applicable to this study.

412 However, the comparison between different optimization tools is not carried out because be-

413 yond the scope of this study.

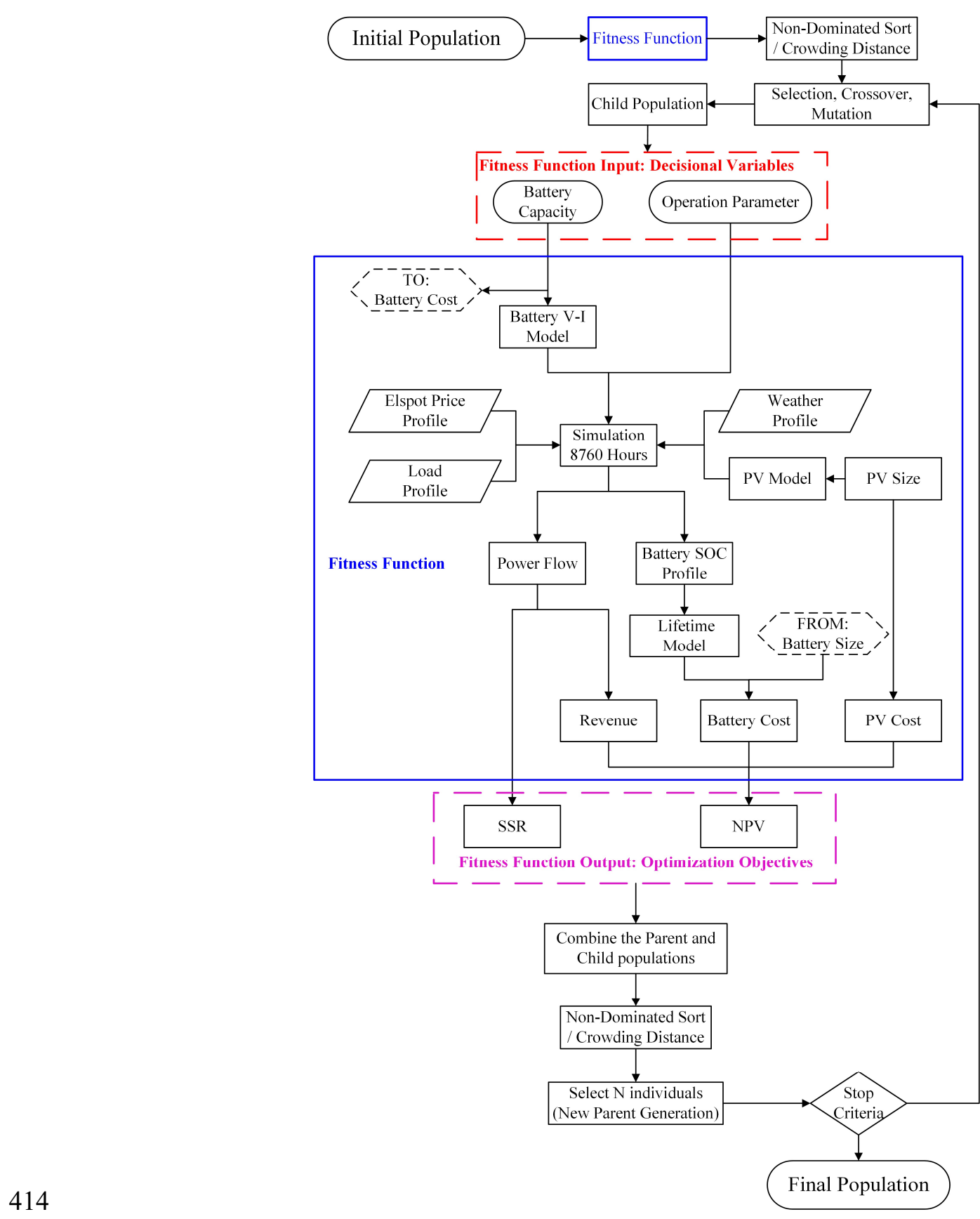




\section{Results and Discussion}

Three rule-based operation strategies are compared in this section. When under the conventional operation strategy, the system's SSR and NPV are obtained with different combinations of PV capacities and battery capacities. For the system under the dynamic price load shifting strategy and the hybrid operation strategy, the relationships between SSR and NPV are represented by the near-optimal Pareto fronts, which are obtained from GA.

\subsection{Conventional Operation Strategy}

The system simulations are carried out with different combinations of battery capacities $(0$ to $800 \mathrm{kWh}, 50 \mathrm{kWh}$ interval) and PV capacities $\left(50,100,150\right.$ and $\left.200 \mathrm{~kW}_{\mathrm{p}}\right)$. The obtained SSR and NPV are shown in Fig. 15 (Red Circle Marker).

At fixed PV size, with the increase of battery capacity, SSR increases until reaching a plateau, while the NPV continuously decreases. This indicates that employing battery will increase the renewable energy penetration level, while the economic performance becomes poorer. The benefit of increased self-consumed electricity is lower than the battery cost. Therefore, it is not attractive for users to install battery for PV systems.

A sensitivity study about the battery price is carried out. When the battery price drops $50 \%$, SSR and NPV of different combinations are shown in Fig. 15 (Blue Triangle Marker). The economic performance is improved. However, the highest NPV values are still with the systems without battery. It indicates that having battery is not economically beneficial even when the battery price drops $50 \%$. The sensitivity study emphasizes that the battery must be better utilized to achieve more economic benefits. 


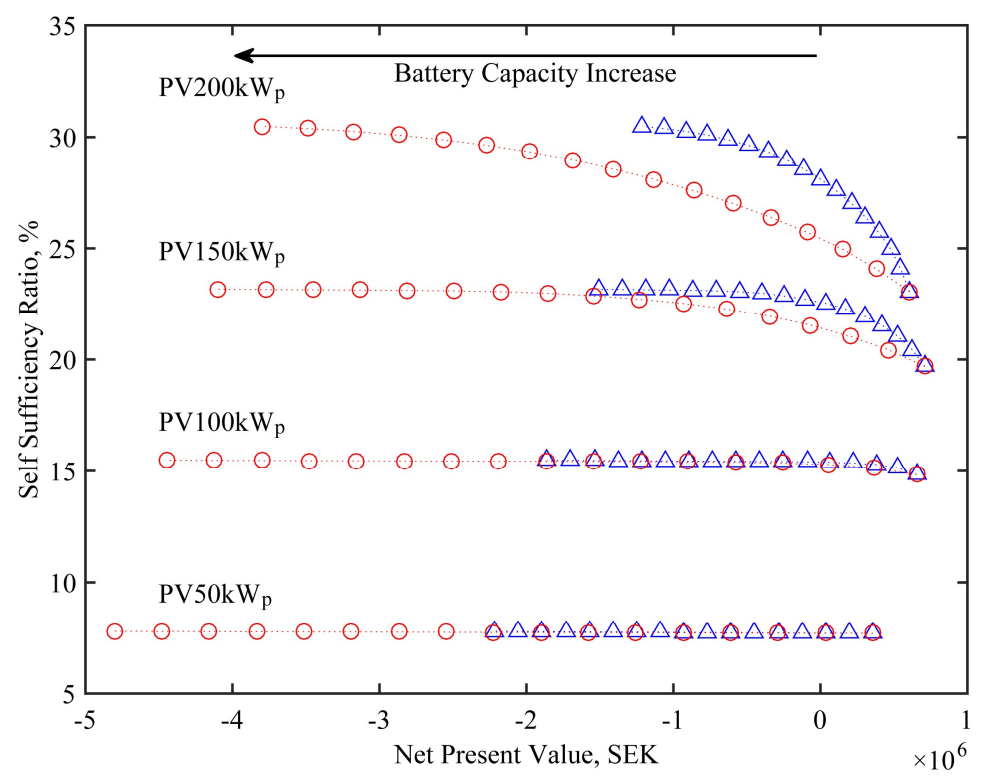

Fig. 15. SSR and NPV for different combinations of PV capacities and battery capacities (Red Circle Marker: 100\% Battery Price, Blue Triangle Marker: 50\% Battery Price)

\subsection{Dynamic Price Load Shifting Strategy}

In this section, the dynamic price load shifting strategy is compared with the conventional operation strategy at fixed PV capacity of $200 \mathrm{~kW}_{\mathrm{p}}$. As shown in Fig. 16, the near-optimal Pareto front for the dynamic price load shifting strategy follows the SSR-NPV curve of the conventional operation strategy. This indicates that the dynamic price load shifting strategy cannot help to improve the system performance regarding SSR and NPV. In the near-optimal Pareto front population, the individuals' decisional variables with respect to their NPV are shown in Fig. 17. The $C A P_{b a t t}$-NPV curve from the dynamic price load shifting strategy overlaps with that from the conventional operation strategy. The high $\left(E l_{r, H}\right)$ and low $\left(E l_{r, L}\right)$ retail electricity price (Fig. 17b) are around 1.05 and $0.85 \mathrm{SEK} / \mathrm{kWh}$, corresponding to 0.22 and 0.02 $\mathrm{SEK} / \mathrm{kWh}$ of the Elspot Price. The Elspot price histogram in Fig. $9 \mathrm{~b}$ shows that there are 712 hours when the Elspot price is lower than $0.22 \mathrm{SEK} / \mathrm{kWh}$. This indicates that at most time of the year, the system follows the operation condition D0, which is identical to the conventional operation strategy. 

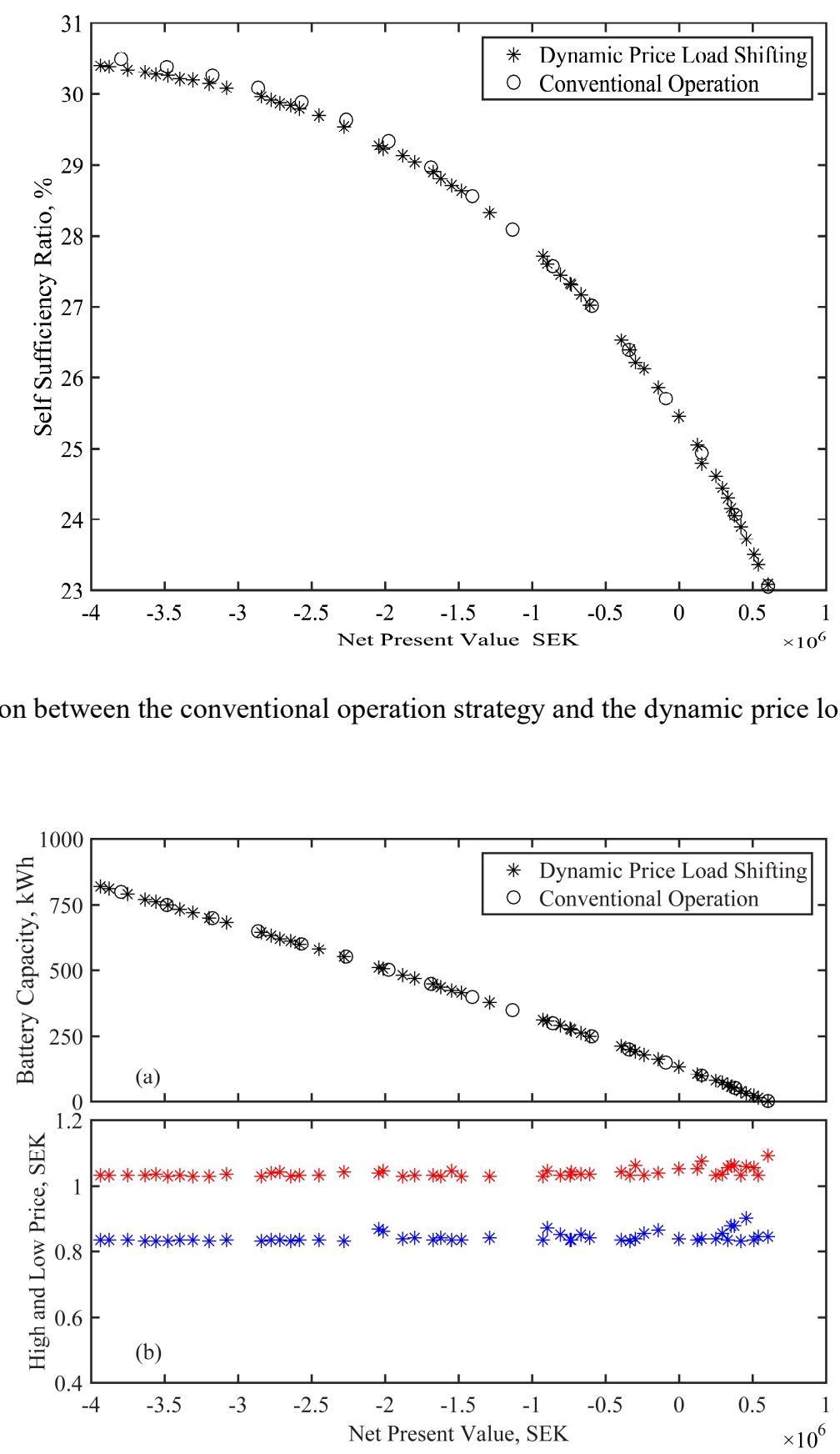

Fig. 17. Variables in the near-optimal Pareto front population: (a)battery capacity $\left(C A P_{b a t t}\right)$ and (b) high $\left(E l_{r, H}\right)$ and low $\left(E l_{r, L}\right)$ retail electricity price

Comparison between the two strategies suggests that the variation in the retail price is not 464 large enough for the dynamic price load shifting strategy to gain extra benefits. Graditi et al. carried out a techno-economic analysis of the load shifting strategy with battery storage system under TOU tariff in Italy [54]. The study also concludes that employing lithium ion battery for 
load shifting is economically unfavorable under the current TOU tariff. However, it should be noted that electricity market is under rapid development. Stable and cheap hydro and nuclear power accounts for the major part of electricity supply now (83.7\% in 2014 [55]). With the increasing capacity of intermittent renewable energy and the gradually shutting down of nuclear power plants, higher variation in the electricity market is expected.

\subsection{Hybrid Operation Strategy}

In this section, the hybrid operation strategy is employed and compared with the conventional operation strategy. The PV capacity is also fixed at $200 \mathrm{~kW}$. As shown in Fig. 18 (Red operation strategy. At low SSR, the hybrid operation strategy has higher NPV than the conventional operation strategy. The NPV difference gradually decreases with the increase of SSR.

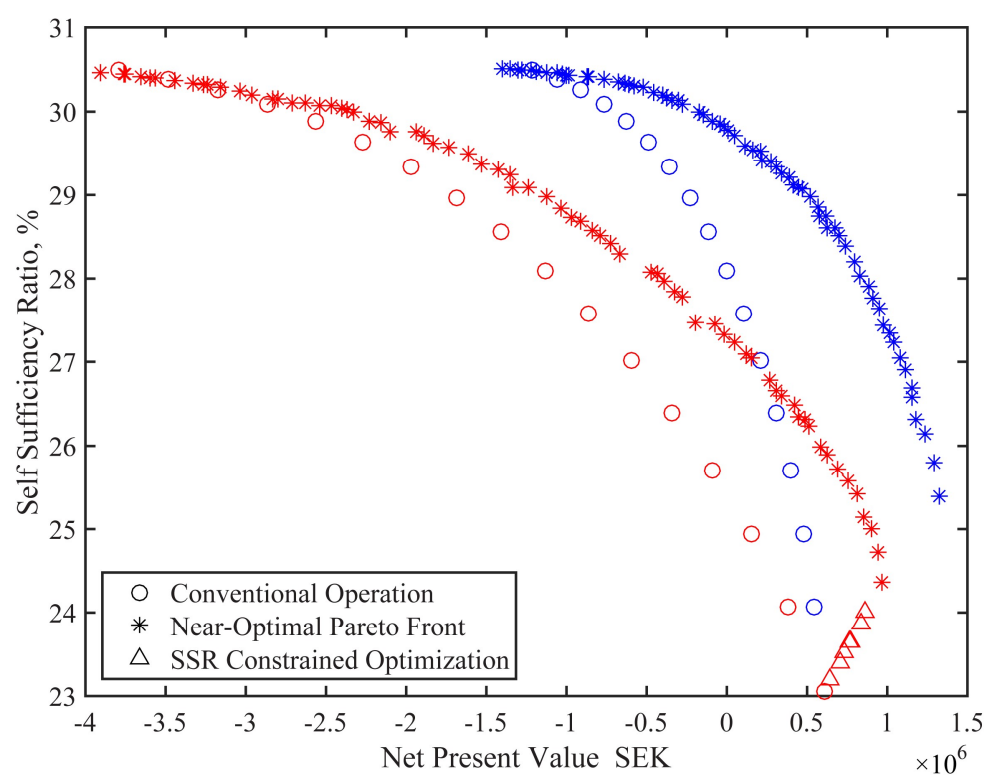

Fig. 18. Comparison between the conventional operation strategy and the hybrid operation strategy (Red Marker: 100\% Battery Price, Blue Marker:50\% Battery Price)

The individuals' decisional variables in the near-optimal Pareto front population are shown 
$24.5 \%$; while if the system only follows the peak shaving strategy, NPV and SSR are $8.3 \times 10^{5}$ SEK and $23.0 \%$. The hybrid operation strategy achieves higher NPV than both conventional operation and peak shaving strategies, while slightly lower SSR than the conventional operation strategy.
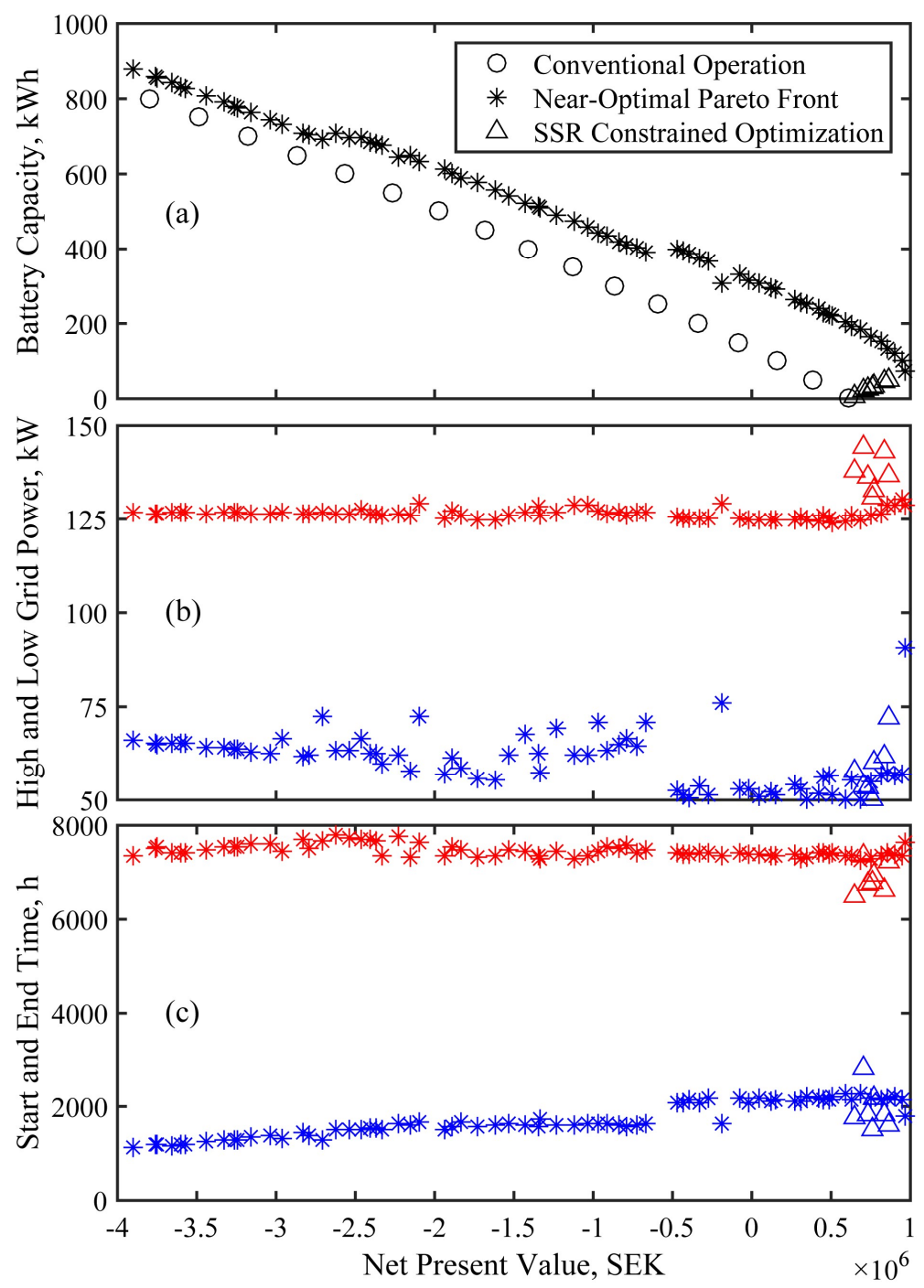

491 Fig. 19. Variables in the near-optimal Pareto front population: (a)battery capacity $\left(C A P_{b a t t}\right) ;(b)$ high $\left(P_{H}\right)$ and low $\left(P_{L}\right)$ power limit; (c) conventional operation start $\left(t_{s}\right)$ and end $\left(t_{e}\right)$ time

The individual with smaller battery capacity (than $72 \mathrm{kWh}$ ) is not obtained through GA. This indicates that the individuals with smaller battery capacities are determined as dominated solutions, and are excluded from the Elitism process. 
Another multi-objective optimization, which constrains battery capacity between 0 and 72 $\mathrm{kWh}$, is carried out. The obtained individuals are not scattered but overlapped (results not shown). Battery capacities in the obtained individuals are crowded between 71 and $72 \mathrm{kWh}$. This indicates that with small battery capacity, SSR and NPV no longer conflict with each other, since otherwise near-optimal Pareto front rather than overlapped individuals would be obtained. To complete the SSR-NPV relationship, the missing individuals are supplemented through single objective GA optimization with constraint of SSR. In this approach, SSR is constrained lower than certain set value through a non-linear constraint function, and single objective optimization is carried out to get the individual which achieves the highest NPV while meeting the that with the increase of battery capacity, both SSR and NPV firstly increase until the turning point. After that, with the increase of battery capacity, SSR increases while NPV decreases. The tion strategy.

513 The results indicate that when battery is smaller than $72 \mathrm{kWh}$, the previously conflicting 514 SSR and NPV change to be consistent. The hybrid operation strategy provides incentive for deploying batteries to PV system, because both higher renewable energy penetration level and better economic performance can be achieved. If batteries are combined with PV, the local grid will also benefit from the improved power quality.

518 A sensitivity study about the battery price is also carried out. If the battery price drops $50 \%$, 519 the near-optimal Pareto front with the hybrid operation strategy and the SSR-NPV curve with 520 the conventional operation strategy will change, as shown in Fig. 18 (Blue Marker). Compared with full price scenarios, the NPV difference between the hybrid operation strategy and the 
conventional operation strategy enlarges, indicating that the hybrid operation strategy becomes more favorable with the decrease of battery price.

As shown in Fig. 19b, with the increase of battery capacity, the assigned time for conventional operation continuously increases ( $t_{s}$ decreases and $t_{e}$ remains almost the same). The reason is further analyzed through two example individuals, which have relatively small and large battery capacity, respectively. The selected individuals' decisional variables, system revenue in the first year and peak power information are presented in Table 3. The two individuals' $P_{G, t}$ and SOC profiles are shown in Fig. 20.

Table 3. Detailed information of two individuals from the near-optimal Pareto front.

\begin{tabular}{lcc}
\hline \multicolumn{1}{c}{ Item } & $\begin{array}{c}\text { Small Battery } \\
\text { Individual }\end{array}$ & $\begin{array}{c}\text { Large Battery } \\
\text { Individual }\end{array}$ \\
\hline $\mathrm{NPV}(\mathrm{SEK})$ & 901184 & -2539753 \\
$\mathrm{SSR}$ & $25.00 \%$ & $30.07 \%$ \\
$C A P_{\text {batt }}(\mathrm{kWh})$ & 122 & 696 \\
$P_{H}(\mathrm{~kW})$ & 129 & 126 \\
$P_{L}(\mathrm{~kW})$ & 57 & 63 \\
$t_{S}(\mathrm{~h})$ & 2192 & 1523 \\
$t_{e}(\mathrm{~h})$ & 7378 & 7728 \\
$R_{E R, 1}(\mathrm{SEK})$ & 183193 & 219603 \\
$R_{E X, 1}(\mathrm{SEK})$ & 11439 & 1201 \\
$R_{P S, 1}(\mathrm{SEK})$ & 44143 & 31650 \\
$R_{1}(\mathrm{SEK})$ & 238775 & 252454 \\
$P_{G, p e a k}(\mathrm{~kW})$ & 129 & 137 \\
$t_{\text {peak }}(\mathrm{h})$ & 548 & 7723 \\
\hline
\end{tabular}

The $P_{G, t}$ and SOC profiles indicate that both individuals carry out peak shaving during cold and dark months and follow conventional operation during warm months. The system revenue $\left(R_{1}\right)$ of the small battery individual does not have significant difference with the large battery individual. The decomposed revenue indicates that the increase in $R_{E X, 1}$ (export revenue) and $R_{P S, 1}$ (peak shaving revenue) largely compensates the decrease in $R_{E R, 1}$ (electricity reduction revenue). As shown in Fig. 20, more electricity is exported (negative grid power) with the small 
battery individual, because its ability for storing excess electricity is lower. Thus, it is less advantageous for small battery individual to follow conventional operation than large battery individual. Therefore, GA assigns more time to carry out peak shaving with the smaller battery individual.

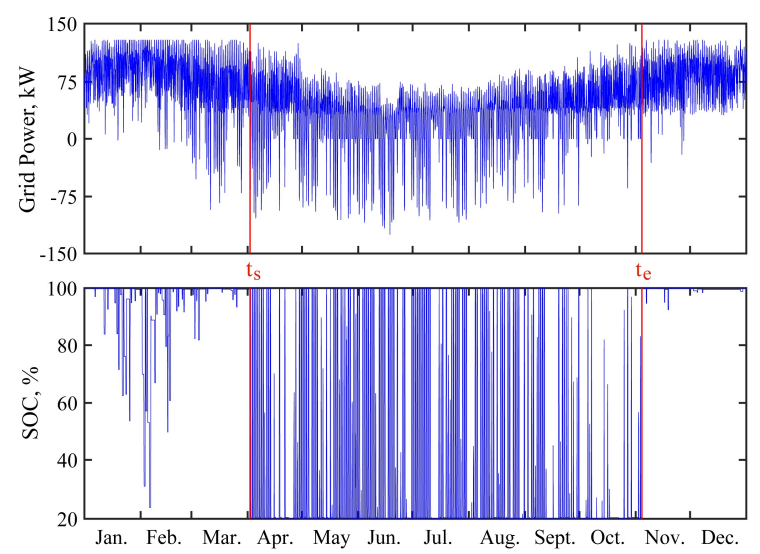

(a)

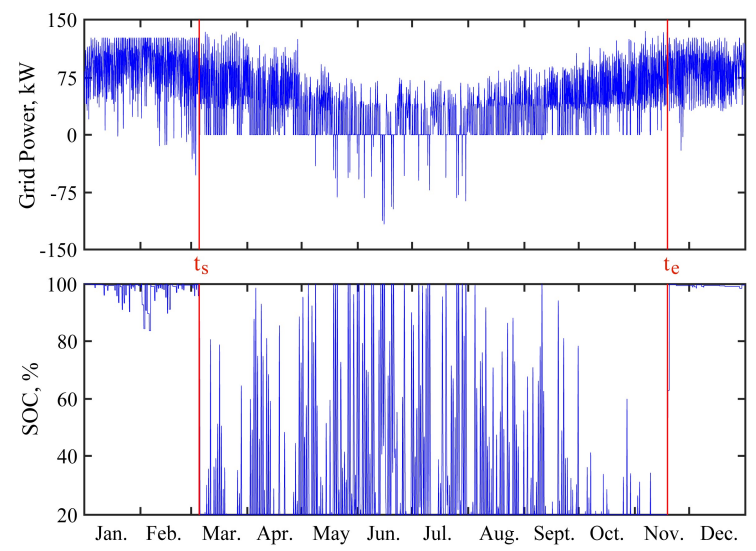

(b)

Fig. 20. $P_{G, t}$ and SOC of the individual with (a) small and (b) large battery capacity

As stated in Section 2.8, GA might lead to the convergence at local minima. To avoid this problem as well as to ensure reproducible results, the optimizations are repeated with different GA configuration parameters. As shown in Fig. 21, the near-optimal solutions with different GA configuration parameters overlap with each other, indicating good reproducibility. Some individuals dominate the individuals of the base case (red asterisk), indicating that GA cannot guarantee optimal solution. However, because of the optimization problem complexity (nonlinear, non-differentiable), the optimality gap cannot be estimated currently. As depicted in Fig. 21 , it can be also concluded that the hybrid operation strategy shows better performance compared to the conventional operation strategy. Indeed, all the near-optimal Pareto fronts outperform the SSR-NPV curve of the conventional operation strategy. 


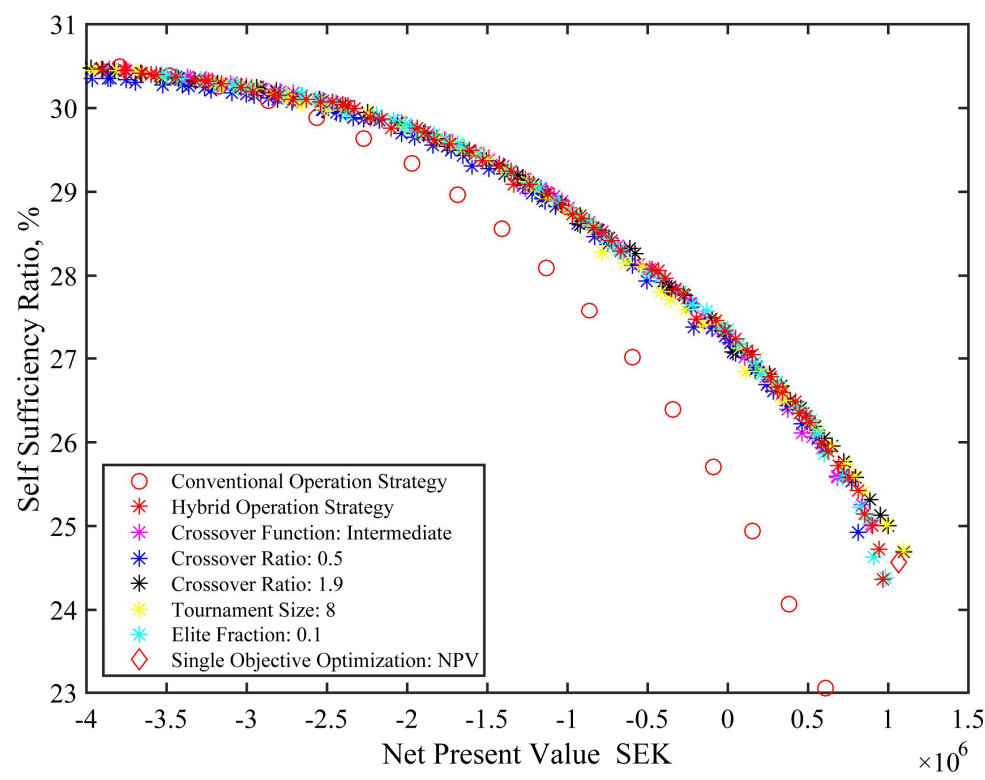

Fig. 21. The near-optimal Pareto fronts obtained from GA with different configuration parameters (Base case: red asterisk, with configuration parameters in Table 2. Changes to the base case are shown in the legend).

\subsection{Overall Approach with Rule-based Operation Strategy and Practical Evaluation}

The flowchart of employing rule-based operation strategy is summarized in Fig. 22. The

flowchart covers stages from system planning to operation. This study focuses on Steps 1-4 and obtains the near-optimal Pareto front. Steps 1-4 are deterministic since they employ representative weather profile, load profile, etc. to obtain the component size and operation parameters. Within Steps 1-4, the uncertainties of weather and load are taken into account, since the employed representative hourly profiles reflect not only the seasonal and daily variations but also the randomness of the values. Moreover, the proposed approach can be easily extended to cover longer period of simulation (i.e. 3 years), which helps to better address the un-certainty issue

569 with longer typical profiles. However, because one-year simulation with hourly interval is widely accepted in current researches [14], this study does not extend to longer period simulatrated to give an overview. 
Uncertainty analysis is important for system sizing in achieving robust system design. The uncertainties in both generation and consumption can influence the system performance both in terms of NPV and SSR. For each deterministic individual from the near-optimal Pareto front, (LOC) [56].

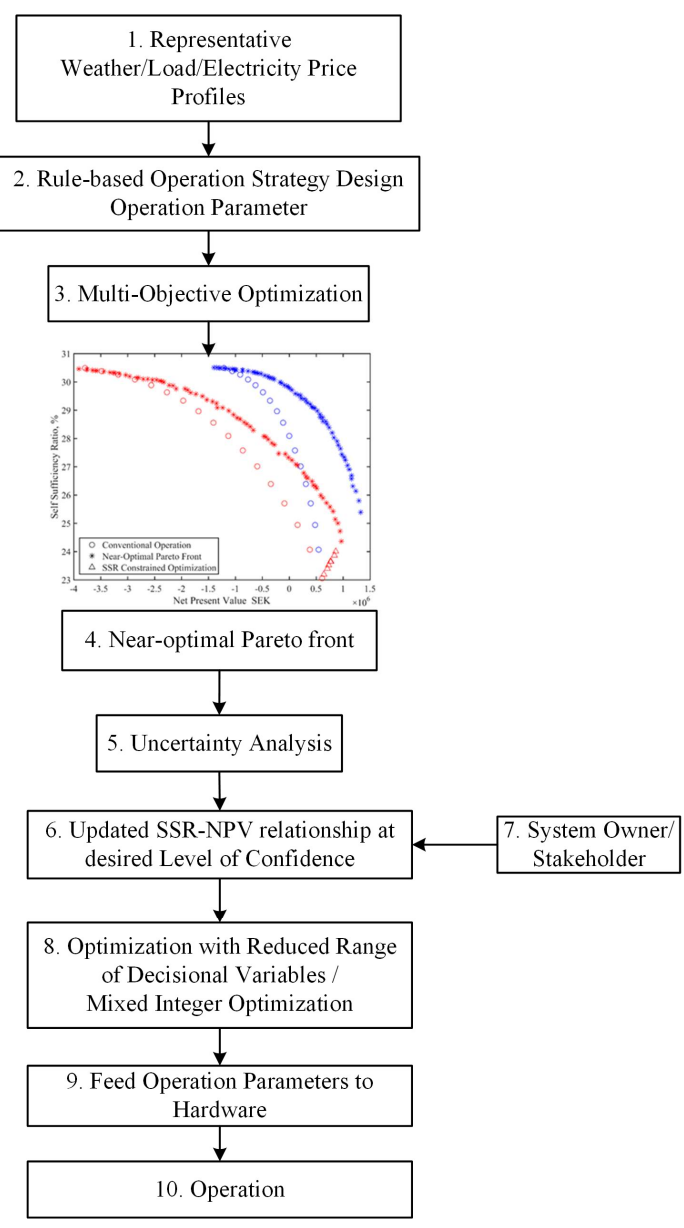

Fig. 22. The overall flowchart of the approach with rule-based operation strategy: from system planning to operation.

The uncertain parameters, as well as their range and form of distribution, are provided in Table 4. The desired LOC are set as 95\%. The system simulations (with determined decisional 584 variables) are repeated 2000 times with random uncertain parameters, which are subjected to the given distribution. An example that refers to the small battery individual of Table 3 is provided in Fig. 23. The NPV and SSR at LOC 95\% are respectively determined when the number 
of trials with higher value is 1900 (95\% of 2000). The NPV and SSR at LOC 95\% are determined as 738346 SEK and $24.91 \%$, respectively. The current uncertainty analysis assumes decisional variables remain unchanged regardless of the PV production and load. However, the operation parameters can be adjusted to fit into the variation in production and load. Less variation and better economic performance can be expected.

Table 4. Uncertainties in PV production, load and Elspot price

\begin{tabular}{cc}
\hline Uncertain Parameter & Distribution \\
\hline$P_{L, t}$ & Uniform $(\delta=0.10)$ \\
$P_{P V, t}$ & Uniform $(\delta=0.10)$ \\
$E l_{w, t}$ & Uniform $(\delta=0.10)$ \\
\hline is the variation limit as a fraction of mean value.
\end{tabular}

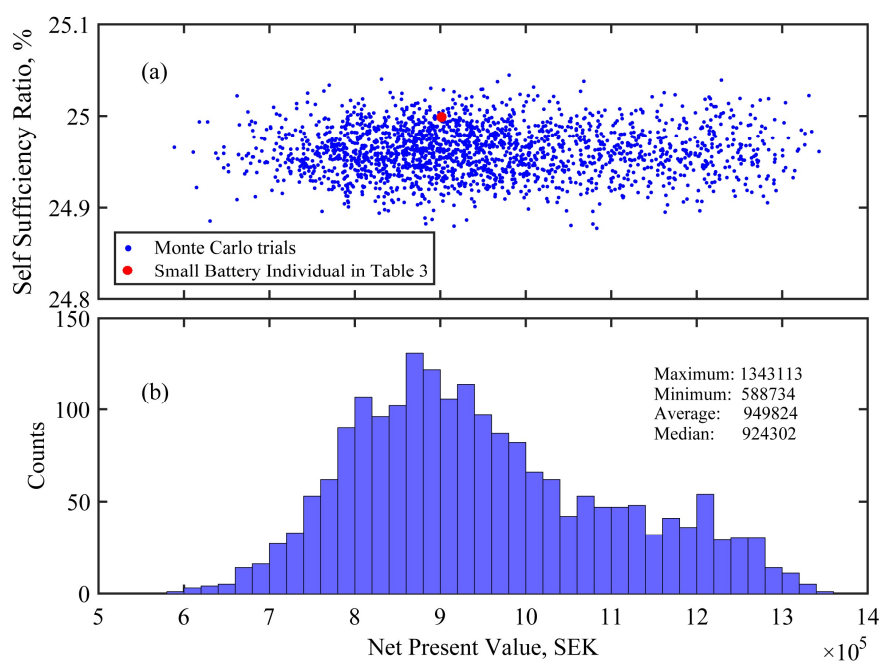

Fig. 23. Uncertainty analysis of the small battery individual from Table 3: (a) scattered plot of SSR vs NPV; (b) histogram of NPV.

With the Monte Carlo simulations, all the individuals of the near-optimal Pareto front can be updated with SSR and NPV at certain LOC. The updated SSR-NPV relationship can give intuitive support for decision-making. Within the following steps, system owner's input (i.e. expected SSR) is required to narrow down the search range; and practical constraint, such as the available battery capacities, need to be included. In Step 9, the hardware layout of carrying 
out the rule-based control can refer to the study by Graditi et al. [57], which presented a prototype for the interface between grid and PV-Lithium ion batteries. The computational requirement during operation is limited because the controller only needs to follow certain rules.

In summary, the proposed approach helps the system owners and designers during the system planning stage to decide the battery capacity with consideration of the operation after installation. The obtained rule-based operation strategy is used to run the system during operation stage.

The battery sizing methods in Ru et al. [26], Gitizadeh et al. [27] and Khalilpour et al. [28] rely on the correct forecasting data. The methods throw little light on the real condition operation when forecasting data cannot be certain. In other words, the optimal scheduling cannot be guaranteed (an example of peak shaving failure due to forecasting error is given in Riffonneau et al. [19]). Moreover, the availability of forecasting equipment has to be practically evaluated for the distributed prosumers.

This study employs a different approach. The optimization process obtains battery capacity and operation parameters. The obtained operation parameters are then used in rule-based operation strategy for real condition operation. The approach actually merges the component sizing and real condition operation as a whole. Moreover, the proposed approach avoids the necessity of forecasting and reduces the complexity of the system. More rapid industrial development can be expected.

One major concern regarding the proposed approach is the applicability to other cases. The studied case has seasonal mismatch between generation and consumption, which provides the chance of employing the proposed hybrid operation strategy. Moreover, the studied case locates in a deregulated electricity market, which provides the building owner access to these economic opportunities [58]. The proposed approach should be tested with more cases and more sophisticated rule-based operation strategies. 
The accuracy of the system is also questioned by the assumptions. The major assumptions include fixed inverter efficiency [26] and that the electricity price policy of the local electricity market remains unchanged within the project life. The system employs single diode PV model [30] and Improved Shepherd Model [39], which respectively has their own assumptions. However, it should also be noted that the approach applies to non-linear and non-differentiable systems. So more detailed models can be incorporated in future works.

\section{Conclusion}

During the planning of grid-connected PV-battery systems, the optimal component sizes need to be determined with consideration of the system operation. In this study, a method that optimizes the battery capacity as well as the rule-based operation strategy is carried out with the multi-objective Genetic Algorithm. The grid-connected PV-battery system is simulated using single diode PV model and Improved Shepherd battery model. Three rule-based operation strategies are designed and compared, drawing the following conclusion:

1) The conventional operation strategy does not bring in economic incentive for PV system to deploy battery even when battery price is lowered $50 \%$.

2) The dynamic price load shifting strategy aims to benefit from the electricity price difference. However, the electricity price variation of the studied case is not significant enough for this operation strategy to gain benefits.

3) The hybrid operation strategy outperforms the conventional operation strategy. Sensitivity study indicates that lowering battery price makes the hybrid operation strategy more favorable. For the studied case, when the battery capacity is larger than $72 \mathrm{kWh}$, there is a trade-off between SSR and NPV. Whereas when the battery capacity is smaller than $72 \mathrm{kWh}, \mathrm{SSR}$ and NPV increase together with the battery capacity. The hybrid operation strategy assigns more operation time to carry out peak shaving for individual with smaller battery capacity. 
654 This work has received funding from KKS Future Energy Profile, European Union's Hori655 zon 2020 (No. 646529) and National High Technology Research and Development Program 656 (863 program) of China (No. 2015AA050402). The authors thank Wallenstam AB with the 657 building load profile and Nord Pool Spot with market price data. Yang Zhang acknowledges 658 the financial support from China Scholarship Council (CSC). 
Table A1. Characterizing parameters in PV single diode model [36].

\begin{tabular}{lll}
\hline Parameter & Explanation & Value \\
\hline$G_{S T C}\left(\mathrm{~W} / \mathrm{m}^{2}\right)$ & Irradiance at Standard Test Condition (STC) & 1000 \\
$T_{S T C}(\mathrm{~K})$ & STC Temperature (Cell Temperature) & 298.15 \\
$I_{P H, S T C}(\mathrm{~A})$ & Photocurrent at STC & 8.731 \\
$\mu_{I S C}(\mathrm{~A} / \mathrm{K})$ & Short current temperature coefficient & 0.005 \\
$I_{O, S T C}(\mathrm{~A})$ & Diode reverse saturation current & $4.41 \times 10^{-10}$ \\
$E_{g, S T C}(\mathrm{eV})$ & Material band gap energy at STC & 1.121 \\
$a_{S T C}(\mathrm{~V})$ & Ideality factor at STC & 1.5819 \\
$R_{S h, S T C}(\Omega)$ & Shunt Resistance at STC & 1519.11 \\
$R_{S}(\Omega)$ & Series Resistance & 0.232 \\
$N O C T\left({ }^{\circ} \mathrm{C}\right)$ & Nominal Operating Cell Temperature & 43.7 \\
\hline
\end{tabular}

661

Table A2. Battery model parameters [39].

\begin{tabular}{cc}
\hline Battery Type & Lithium Ion \\
\hline Nominal Voltage $(\mathrm{V})$ & 3.3 \\
Nominal Capacity $(\mathrm{Ah})$ & 2.3 \\
$E_{0}(\mathrm{~V})$ & 3.366 \\
$\mathrm{~K}(\mathrm{~V} /(\mathrm{Ah})$ or $\Omega)$ & 0.0076 \\
$\mathrm{R}(\Omega)$ & 0.01 \\
$\mathrm{~A}(\mathrm{~V})$ & 0.26422 \\
$\mathrm{~B}(\mathrm{Ah})^{-1}$ & 26.5487 \\
Cut off voltage(V) & 3 \\
Charge control voltage $(\mathrm{V})$ & 4 \\
Maximal Current & $\mathrm{C} / 3$ \\
\hline
\end{tabular}

663

664

Table A3. Estimated computational time for covering possible combinations of the decisional variables

\begin{tabular}{cccc}
\hline Decisional Variables & Range & Interval & Points \\
\hline$C A P_{\text {batt }}(\mathrm{kWh})$ & $0-1000$ & 10 & 100 \\
$P_{H}(\mathrm{~kW})$ & $110-160$ & 5 & 10 \\
$P_{L}(\mathrm{~kW})$ & $50-120$ & 5 & 14 \\
$t_{s}$ & $1000-3000$ & 100 & 20 \\
$t_{e}$ & $6000-8000$ & 100 & 20 \\
\hline \multicolumn{3}{c}{ Total Combinations } & 5600000 \\
\hline Estimated Computational Time & 1.3 Years \\
(Parallel Computing with i7-4790 CPU)
\end{tabular}

665 
667 [1] IEA-PVPS. Snapshot of global PV markets. 2015 <http://www.iea-pvps.org/>.

668 [2] IEA-PVPS. Trends 2014 in Photovoltaic applications. $2014<\underline{\text { http://www.iea-pvps.org/>. }}$

669 [3] Marzband M, Moghaddam MM, Akorede MF, Khomeyrani G. Adaptive load shedding scheme for 670 frequency stability enhancement in microgrids. Electr Pow Syst Res 2016; 140: 78-86.

671 [4] Teleke S, Baran ME, Bhattacharya S, Huang AQ. Rule-based control of battery energy storage for dispatching intermittent renewable sources. IEEE Trans Sustain Energy 2010; 1: 117-24.

[5] Sommerfeldt N, Madani H. On the use of hourly pricing in techno-economic analyses for solar photovoltaic systems. Energy Convers Manage 2015; 102: 180-9.

[6] Luthander R, Widén J, Nilsson D, Palm J. Photovoltaic self-consumption in buildings: A review. Appl Energy 2015; 142: 80-94.

[7] Dusonchet L, Ippolito MG, Telaretti E, Zizzo G, Graditi G. An optimal operating strategy for combined RES-based generators and electric storage systems for load shifting applications. Fourth International Conference on Power Engineering, Energy and Electrical Drives 2013. pp. 552-7. [8] Zheng M, Meinrenken CJ, Lackner KS. Smart households: Dispatch strategies and economic analysis of distributed energy storage for residential peak shaving. Appl Energy 2015; 147: 246-57. [9] Lu Y, Wang S, Shan K. Design optimization and optimal control of grid-connected and standalone nearly/net zero energy buildings. Appl Energy 2015; 155: 463-77.

[10] Yang $\mathrm{H}$, Zhou W, Lou C. Optimal design and techno-economic analysis of a hybrid solar-wind power generation system. Appl Energy 2009; 86: 163-9.

[11] Paliwal P, Patidar NP, Nema RK. Determination of reliability constrained optimal resource mix for an autonomous hybrid power system using particle swarm optimization. Renew Energy 2014; 63: 194-204.

[12] Xu L, Ruan X, Mao C, Zhang B, Luo Y. An improved optimal sizing method for wind-solar-battery hybrid power system. IEEE Trans Sustain Energy 2013; 4: 774-85.

[13] Mulder G, Ridder FD, Six D. Electricity storage for grid-connected household dwellings with PV panels. Sol Energy 2010; 84: 1284-93.

[14] Bortolini M, Gamberi M, Graziani A. Technical and economic design of photovoltaic and battery energy storage system. Energy Convers Manage 2014; 86: 81-92.

[15] Zhou N, Liu N, Zhang J, Lei J. Multi-objective optimal sizing for battery storage of PV-based microgrid with demand Response. Energies 2016; 9: 591.

[16] Mokhtari G, Nourbakhsh G, Gosh A. Optimal sizing of combined PV- energy storage for a gridconnected residential building. Advances in Energy Engineering 2013; 1: 53-65.

[17] Marzband M, Sumper A, Ruiz-Álvarez A, Domínguez-García JL, Tomoiagă B. Experimental evaluation of a real time energy management system for stand-alone microgrids in day-ahead markets. Appl Energy 2013; 106: 365-76.

[18] Lu B, Shahidehpour M. Short-term scheduling of battery in a grid-connected PV/battery system. IEEE Trans Power Syst 2005; 20: 1053-61.

[19] Riffonneau Y, Bacha S, Barruel F, Ploix S. Optimal power flow management for grid connected PV systems with batteries. IEEE Trans Sustain Energy 2011; 2: 309-20.

[20] Li J, Danzer MA. Optimal charge control strategies for stationary photovoltaic battery systems. J Power Sources 2014; 258: 365-73.

[21] Marzband M, Sumper A, Domínguez-García JL, Gumara-Ferret R. Experimental validation of a real time energy management system for microgrids in islanded mode using a local day-ahead electricity market and MINLP. Energy Convers Manage 2013; 76: 314-22.

[22] Marzband M, Yousefnejad E, Sumper A, Domínguez-García JL. Real time experimental implementation of optimum energy management system in standalone Microgrid by using multilayer ant colony optimization. International Journal of Electrical Power \& Energy Systems 2016; 75: 265-74. 
[23] Marzband M, Ghadimi M, Sumper A, Domínguez-García JL. Experimental validation of a real-time energy management system using multi-period gravitational search algorithm for microgrids in islanded mode. Appl Energy 2014; 128: 164-74.

[24] Marzband M, Parhizi N, Adabi J. Optimal energy management for stand-alone microgrids based on multi-period imperialist competition algorithm considering uncertainties: experimental validation. Int Trans Electr Energ Syst 2016; 26: 1358-72.

721 [25] Marzband M, Azarinejadian F, Savaghebi M, Guerrero JM. An optimal energy management chain. IEEE Syst J 2015; PP: 1-11.

[26] Ru Y, Jan K, Sonia M. Storage size determination for grid-connected Photovoltaic systems. IEEE Trans Sustain Energy 2013; 4: 68-81.

[27] Gitizadeh M, Fakharzadegan H. Battery capacity determination with respect to optimized energy dispatch schedule in grid-connected photovoltaic (PV) systems. Energy 2014; 65: 665-74.

[28] Khalilpour R, Vassallo A. Planning and operation scheduling of PV-battery systems: A novel methodology. Renew Sust Energy Rev 2016; 53: 194-208.

[29] OptiCE. <www.optice.net> [assessed 11.8.2016].

[30] De Soto W, Klein SA, Beckman WA. Improvement and validation of a model for photovoltaic array performance. Sol Energy 2006; 80: 78-88.

[31] Duffie JA, Beckman WA. Solar engineering of thermal processes. 4th ed. Wiley New York etc.2013.

[32] Dolara A, Leva S, Manzolini G. Comparison of different physical models for PV power output prediction. Sol Energy 2015; 119: 83-99.

[33] Aurilio G, Balato M, Graditi G, Landi C, Luiso M, Vitelli M. Fast hybrid MPPT technique for Photovoltaic applications: numerical and experimental Validation. Advances in Power Electronics 2014; 2014: 15.

[34] Adinolfi G, Graditi G, Siano P, Piccolo A. Multiobjective Optimal Design of Photovoltaic Synchronous Boost Converters Assessing Efficiency, Reliability, and Cost Savings. IEEE Trans Ind Informat 2015; 11: 1038-48.

[35] Merei G, Berger C, Sauer DU. Optimization of an off-grid hybrid PV-Wind-Diesel system with different battery technologies using genetic algorithm. Sol Energy 2013; 97: 460-73.

[36] Blair N, Dobos AP, Freeman J, Neises T, Wagner M, Ferguson T, et al. System advisor model, sam 2014.1. 14: general description. 2014 <https://www.nrel.gov/publications>.

[37] Dunn B, Kamath H, Tarascon J-M. Electrical energy storage for the grid: A battery of choices. Science 2011; 334: 928-35.

[38] Nykvist B, Nilsson M. Rapidly falling costs of battery packs for electric vehicles. Nat Clim Change 2015; 5: 329-32.

[39] Tremblay O, Dessaint L-A. Experimental validation of a battery dynamic model for EV applications. World Electric Vehicle Journal 2009; 3: 1-10.

[40] Wang J, Liu P, Hicks-Garner J, Sherman E, Soukiazian S, Verbrugge M, et al. Cycle-life model for graphite-LiFePO4 cells. J Power Sources 2011; 196: 3942-8.

[41] Mansor NII, Abdullah S, Ariffin AK, Syarif J. A review of the fatigue failure mechanism of metallic materials under a corroded environment. Eng Fail Anal 2014; 42: 353-65.

[42] Downing SD, Socie DF. Simple rainflow counting algorithms. Int J Fatigue 1982; 4: 31-40.

[43] Zhang Z, Wang J, Wang X. An improved charging/discharging strategy of lithium batteries considering depreciation cost in day-ahead microgrid scheduling. Energy Convers Manage 2015; 105: 675-84.

[44] Yang Z, Zhang J, Kintner-Meyer MCW, Lu X, Choi D, Lemmon JP, et al. Electrochemical energy storage for green grid. Chem Rev 2011; 111: 3577-613.

[45] List of all Meteonorm features <http://www.meteonorm.com/> [assessed 15.3.2016].

[46] Zhang Y, Lundblad A, Campana PE, Yan J. Employing battery storage to increase photovoltaic self-sufficiency in a residential building of Sweden. Energy Proc 2016; 88: 455-61. 
[47] Lindahl J. National survey report of PV power applications in SWEDEN. 2015 <http://www.iea-

767 pvps.org/>.

768 [48] Nord Pool Spot. <http://www.nordpoolspot.com/> [assessed 11.3.2016].

769 [49] Sweden interest rates. <http://sweden.deposits.org/> [assessed 16.5.2016].

770 [50] Tesla home battery. <https://www.tesla.com/powerwall> [assessed 11.8.2016].

771 [51] Konak A, Coit DW, Smith AE. Multi-objective optimization using genetic algorithms: A tutorial.

772 Reliab Eng Syst Safe 2006; 91: 992-1007.

773 [52] Chauhan A, Saini RP. A review on Integrated Renewable Energy System based power generation

774 for stand-alone applications: Configurations, storage options, sizing methodologies and control.

775 Renew Sust Energy Rev 2014; 38: 99-120.

776 [53] Deb K, Agrawal S, Pratap A, Meyarivan T. A fast elitist non-dominated sorting genetic algorithm

777 for multi-objective optimization: NSGA-II. International Conference on Parallel Problem Solving From

778 Nature. Springer, Berlin Heidelberg, 2000. pp. 849-58.

779 [54] Graditi G, Ippolito MG, Telaretti E, Zizzo G. Technical and economical assessment of distributed

780 electrochemical storages for load shifting applications: An Italian case study. Renew Sust Energy Rev

$7812016 ; 57: 515-23$.

782 [55] Statistics Sweden-Energy. <http://www.scb.se/en /Finding-statistics/Statistics-by-subject-

783 area/Energy/> [assessed 24.5.2016].

784 [56] Maheri A. Multi-objective design optimisation of standalone hybrid wind-PV-diesel systems

785 under uncertainties. Renew Energy 2014; 66: 650-61.

786 [57] Graditi G, Ippolito MG, Telaretti E, Zizzo G. An innovative conversion device to the grid interface of combined RES-based generators and electric storage systems. IEEE Trans Ind Electron 2015; 62: 2540-50.

789 [58] Marzband M, Javadi M, Dom JL, xed, nguez G, xed, et al. Non-cooperative game theory based energy management systems for energy district in the retail market considering DER uncertainties. IET Gener Transm Distrib 2016; 10: 2999-3009. 